\title{
Les Wayana de Guyane française sur les traces de leur histoire
}

Cartographie participative sur le Litani (Aletani) et mémoire orale

Wayana of French Guiana on the trail of their history: Participatory mapping of the Litani (Aletani) and oral memory

Marie Fleury, Tasikale Alupki, Aimawale Opoya et Waiso Aloïké

\section{OpenEdition}

\section{Journals}

Édition électronique

URL : http://journals.openedition.org/ethnoecologie/2711

DOI : 10.4000/ethnoecologie.2711

ISSN : 2267-2419

\section{Éditeur}

Laboratoire Eco-anthropologie et Ethnobiologie

\section{Référence électronique}

Marie Fleury, Tasikale Alupki, Aimawale Opoya et Waiso Aloïké, « Les Wayana de Guyane française sur les traces de leur histoire », Revue d'ethnoécologie [En ligne], 9 | 2016, mis en ligne le 01 juillet 2016, consulté le 30 avril 2019. URL : http://journals.openedition.org/ethnoecologie/2711 ; DOI : 10.4000/ ethnoecologie. 2711

Ce document a été généré automatiquement le 30 avril 2019

\section{cc) (†) $९$}

Revue d'ethnoécologie est mis à disposition selon les termes de la licence Creative Commons Attribution - Pas d'Utilisation Commerciale - Pas de Modification 4.0 International. 


\title{
Les Wayana de Guyane française sur les traces de leur histoire
}

\author{
Cartographie participative sur le Litani (Aletani) et mémoire orale \\ Wayana of French Guiana on the trail of their history: Participatory mapping of \\ the Litani (Aletani) and oral memory
}

\author{
Marie Fleury, Tasikale Alupki, Aimawale Opoya et Waiso Aloïké
}

\section{NOTE DE L'AUTEUR}

Notre programme PPR AMAZ de l'IRD « Plantes, lieux, objets et mots : marqueurs territoriaux et identitaires, indicateurs de dynamiques socioenvironnementales et patrimoniales » nous a permis de financer les premières étapes de ce travail (2012). Le programme GUYAMAZON DIPOLOPP a également permis de financer une partie du projet, complétés par des crédits de recherche de l'UMR 208 PALOC MNHN-IRD.

À la mémoire de Jean Hurault et Hervé Rivière.

1 Roucouyennes, Rocoyens, Orkokoyana, Urukuyana, Upului, Kukujana, Oyana, Wayana, autant de dénominations pour ce peuple karib né de la fusion de plusieurs groupes dans les TumucHumac, région mythique ${ }^{1}$ du partage des eaux dans l'extrême sud de la Guyane ${ }^{2}$.

2 Mis à part quelques témoignages historiques, des chapitres de monographies et différents récits d'explorateurs ( $c f$. bibliographie), l'histoire des Wayana est restée assez mal connue, jusqu'aux travaux de Chapuis (Chapuis \& Rivière 2003, Chapuis 2007) notamment son essai d'ethnosociogenèse wayana qui nous livre une histoire orale des Wayana. Cet ouvrage retrace la fusion de différents groupes culturels $\left(\right.$ clans $\left.^{3}\right)$ qui a mené à la création de ce que nous avons coutume d'appeler l'ethnie ou le peuple wayana.

3 Ces groupes culturels venus du Brésil vivaient sur le Jari et le Paru, depuis au moins le $\mathrm{XV}^{\mathrm{e}}$ siècle. Attaqués par des chasseurs d'esclaves armés par les Portugais, notamment des 
Wayãpi, ils se sont réfugiés dans la région des Tumuc-Humac au XVIII siècle (Grenand 1982). L'histoire orale des Wayana est riche d'anecdotes et d'évènements qui se seraient déroulés durant cette période. Le guerrier Kailawa, héros de l'histoire wayana dont les Anciens aiment à raconter les exploits encore aujourd'hui, menait alors une guerre sans merci contre les autres groupes, tuant tous les adultes et ne gardant que les jeunes enfants pour les élever: C'est l'origine du peuple wayana issu de la fusion de tous les peuples dont on connait encore les noms des clans formateurs. Après avoir vécu un certain temps dans la région des Tumuc-Humac, les Wayana ont descendu progressivement les rivières Marouini et Litani, en déplaçant leurs villages, pour se rapprocher des lieux de commerce des produits occidentaux (Chapuis 2007).

Depuis les années 1950, les Wayana ont sédentarisé leurs villages, sous l'influence des missions protestantes nord-américaines et des administrations françaises principalement à Twenké, Taluwen et Antécume pata (sur le Litani), Elahé, Kayodé (sur le Tampok), dans la région située en aval des grands sauts du Litani. S'il existe aussi quelques villages wayana sur le Lawa, cette dernière portion du Maroni est surtout occupée par le peuple boni (Aluku) formé par des descendants de Noirs marrons ayant fui les plantations hollandaises au $\mathrm{XVIII}^{\mathrm{e}}$ et s'étant réfugiés du côté français du Maroni à partir de 1776 (Moomou 2004).

5 Dans cet article, nous retraçons une mémoire sur la manière dont les Wayana ont progressivement descendu la rivière Litani depuis ses sources dans les Tumuc-Humac, jusqu'à la région où ils habitent actuellement. Ce travail se base sur la tradition orale, documentée lors d'un travail de cartographie participative mené entre 2012 et 2015, puis croisée avec les sources écrites. Quels ont été les différentes étapes et les principaux obstacles à cette migration le long de cet affluent principal du Maroni ? C'est la question à laquelle nous allons essayer de répondre en revenant sur les anciens lieux habités à partir de l'amont du fleuve Maroni.

\section{La mise en place du projet de cartographie}

6 Aujourd'hui, les Anciens des Wayana connaissent encore les noms et les emplacements des villages et des campements habités par leurs ancêtres tout au long de ces migrations depuis les Tumuc-Humac. Les jeunes Wayana, quant à eux souhaitent mieux connaître leur histoire et la rivière qu'ils fréquentent régulièrement pour leurs différentes activités. C'est sur la base de ce constat qu'est né notre intérêt pour documenter et enregistrer les récits et les connaissances sur les lieux et les événements du passé avec un projet de cartographie participative. Celui-ci concrétise en partie les ambitions, parfois anciennes, de collaboration des Wayana avec des chercheurs et des institutions qui partagent un intérêt pour l'histoire de la région.

Le Parc Amazonien de Guyane (PAG) ayant parmi ses objectifs une meilleure connaissance du patrimoine naturel, culturel, et paysager de son territoire, a soutenu des initiatives dans ce sens, telle la recherche menée par Pierre Grenand et ses collaborateurs sur l'Oyapock, avec notamment le recueil systématique des toponymes vernaculaires dans cette région.

Sous l'impulsion de Jean Hurault, qui avait confié l'organisation de cette mission à l'ethnobotaniste Marie Fleury, un premier travail de reconnaissance historique avait déjà été réalisé en 1999 avec plusieurs Anciens des communautés wayana et aluku sur le 
Marouini. En effet ce géographe de l'IGN, connu pour ses travaux ethnographiques chez les Boni et les Wayana, regrettait de ne pas avoir fait de mission de reconnaissance des anciens sites habités. Il finança cette première mission dont l'objectif était de remonter la rivière Marouini avec des Anciens porteurs de connaissance afin de répertorier et géolocaliser les anciens sites marqués par l'histoire (Fleury 1999a). Les travaux menés avec d'autres chercheurs, notamment ceux qui ont travaillé sur la tradition orale (Chapuis et Rivière 2003) mais aussi sur la langue ou la culture matérielle, participent également du renforcement de l'intérêt des Wayana pour leur patrimoine et leur histoire.

Ce travail de cartographie sur le Litani est donc le résultat de différentes volontés de mieux connaître le territoire, d'une demande de la communauté pour revenir sur ces lieux de l'amont, mais aussi d'une réflexion sur les méthodologies de cartographie participative pour la valorisation des savoirs locaux (Robert \& Fleury 2012). Nous considérons en effet que la carte est un instrument de choix pour renforcer les liens entre habitants, recherche scientifique et politiques publiques, et que la mémoire avec l'histoire des lieux de vie font partie intégrante du patrimoine culturel immatériel. Celuici étant fortement fragilisé face à la mondialisation et à l'intégration croissante des Wayana dans le système français, notre objectif est de participer à sa sauvegarde à travers ce travail de cartographie réalisé avec les Wayana.

Que nous disent les Anciens de ces lieux habités autrefois par les Wayana? À quels événements du passé se rapportent-ils? Comment la toponymie des lieux-dits, villages, et campements peut-elle nous renseigner sur la culture, l'histoire ou les représentations de la nature? Telles sont les principales questions qui sous-tendent notre travail.

De plus, le partenariat avec le Parc Amazonien pour la réalisation de ces cartes permet aux toponymes recueillis d'être mieux pris en compte dans les cartes officielles ${ }^{4}$ éditées par le PAG et par l'IGN (Institut Géographique National). Pour les Wayana, il s'agit en outre d'une réappropriation symbolique de leurs anciens territoires de vie. Soulignons que c'est un territoire contesté par le Suriname, et soumis actuellement à une pression très forte de la part d'orpailleurs clandestins. L'intérêt renouvelé pour les cartes s'inscrit aussi dans des contextes de menaces territoriales.

\section{La méthodologie aux différentes étapes du projet}

Le projet de cartographie participative du Litani a été rédigé en 2012 après discussion avec des habitants et les représentants de l'association Kalipo au village de Taluwen et la demande formelle d'autorisation auprès des chefs coutumiers. Dans ce cadre, nous avons aussi souhaité et signé une convention tripartite entre Kalipo, association culturelle wayana présidée par Tasikale Alupki, le Muséum National d'Histoire Naturelle, représentée en Guyane par Marie Fleury, et le Parc Amazonien de Guyane, chargé de réaliser les cartes à partir des éléments fournis 5 .

13 Les premiers entretiens avec les Anciens ont été réalisés au village de Taluwen en novembre 2012 : une cinquantaine d'anciens lieux de vie a été énumérée et localisée avec plus ou moins de précision sur la carte IGN de la Guyane. Cette première enquête confirmait la richesse des connaissances sur le sujet, et a permis de discuter des modalités à adopter pour la future mission sur le terrain et du choix des participants et meilleurs connaisseurs des lieux. En effet, il a paru indispensable à tous de parcourir le territoire, 
c'est à dire de remonter le fleuve, à la fois pour repérer les sites avec une information précise et géolocalisée et pour se remémorer in situ des principaux faits s'y rapportant.

Après différentes réunions de travail au village, deux missions de reconnaissance ont été organisées consécutivement en remontant en pirogue, avec des Anciens connaisseurs et intéressés par le travail, la rivière du Litani (Aletani) jusqu'à l'amont, au pied des TumucHumac.

15 La première mission de reconnaissance a eu lieu en août 2013 (Figure 1), avec la participation de trois Anciens : Pidima, fondateur et chef du village Pidima, nommé en réalité Pilima par les Wayana, il était âgé de 80 ans au moment de la première expédition ; c'est un grand connaisseur de l'histoire locale. Il est le descendant direct d'un des pionniers de cette histoire.

Figure 1 : Expédition 2013. Au premier plan Halanau, derrière Palimino et au fond Tasikale

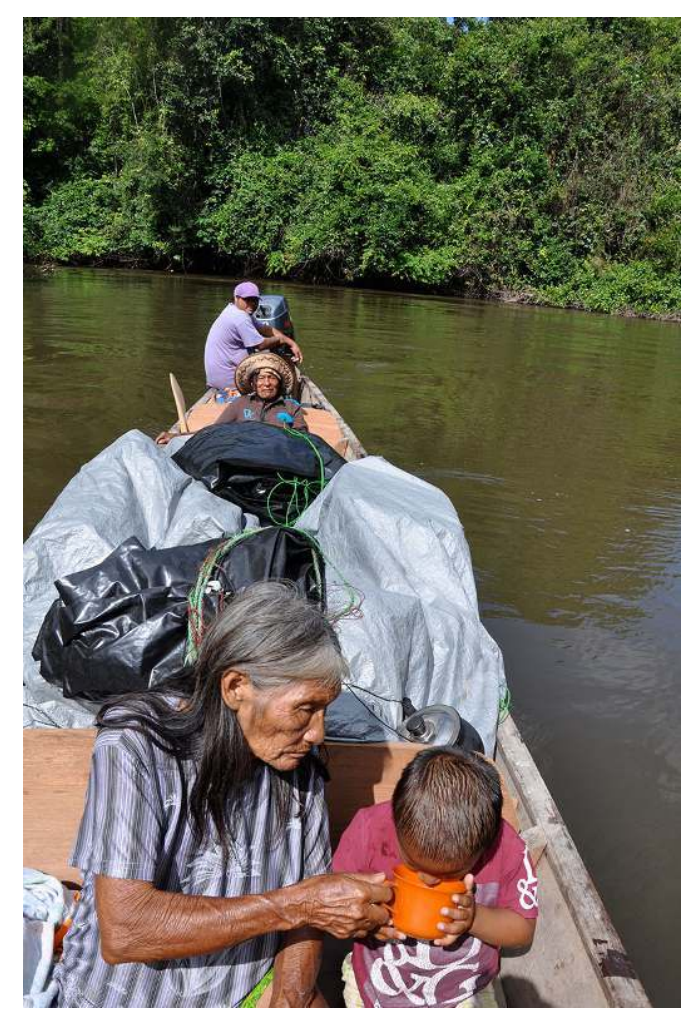

Cliché M. Fleury

16 Halanau, tante de Tasikale Alupki, co-auteur de cet article, était âgée d'environ 80 ans au moment du voyage. Elle vit dans le village de son mari Palimino, et connaît également bien l'histoire orale. Enfin, Palimino, le mari de Halanau et fondateur du village de Palimino, nous a accompagné.

Pour conserver une trace matérielle de ces retrouvailles entre lieux d'autrefois et mémoire orale, nous avons réalisé les enregistrements filmiques des témoignages des Anciens racontant les histoires et les mythes qui jalonnent ce parcours.

Ces premiers éléments géoréférencés obtenus en 2013 nous ont permis de réaliser, en partenariat avec le Parc amazonien et avec l'aide de Pierre Joubert, la première ébauche d'une carte historique du Maroni en mars 2014. Cette dernière a servi de base à de nouvelles discussions à Taluwen en avril 2014 lorsqu'elle a été rediscutée, commentée et 
corrigée avec les les Anciens et autres villageois. À cette occasion, il fut également convenu d'organiser un autre voyage pour compléter le travail déjà réalisé.

Une nouvelle mission de reconnaissance a été organisée en août 2015 avec deux autres détenteurs de savoirs wayana, qui n'avaient pas pu se joindre à nous en 2013 (Figure 2). Haïwé Aloïké est un chef coutumier reconnu capitaine par les autorités françaises et âgé d'environ 75 ans au moment du voyage de 2015. C'est le grand père de Waiso Aloïké, coauteur de cet article, et le beau-frère du grand man Amaïpoti Twenké, fils de Twenké, fondateur du village actuel de Twenké. Kali, âgée d'environ 70 ans en 2015, était aussi du voyage ; elle est fille de Janamale, fondateur (tamusi $\left.{ }^{6}\right)$ de plusieurs villages, et femme de Ëputu, capitaine du village actuel de Kumakahpan. C'est aussi la tante de Tasikale.

Figure 2 : Expédition 2015 au centre de la pirogue Kali et Haiwé (avec casquettes)

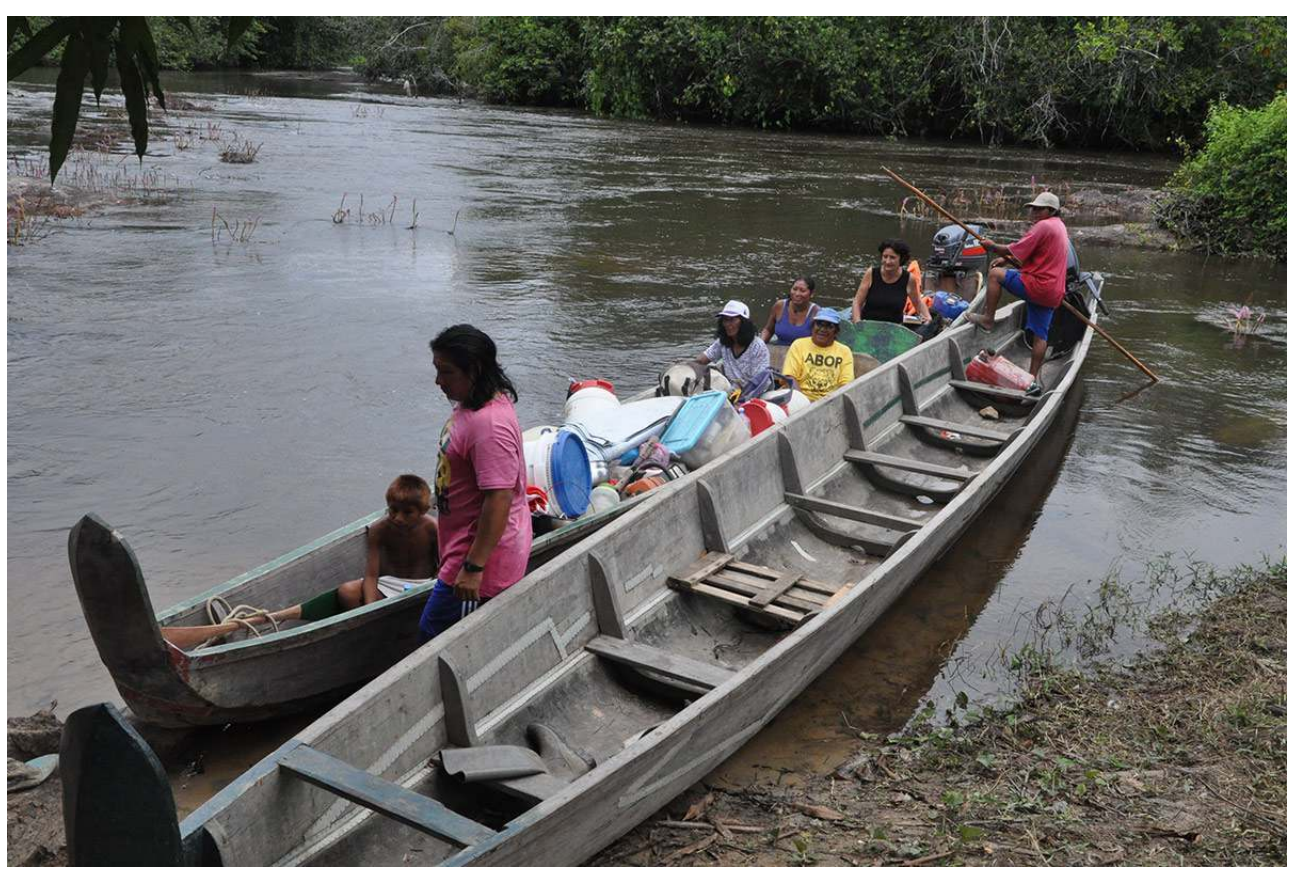

Cliché M. Fleury

\section{Résultats}

\section{Les sources orales}

Si de mémoire, les Anciens nous avaient cité une cinquantaine d'anciens villages, les missions de reconnaissance nous ont permis d'identifier environ 130 toponymes, lieuxdits, anciens villages, campements, sauts (rapides) ou criques (petites rivières) auxquels sont rattachés l'histoire des Wayana, dont plus de 70 anciens villages. Ainsi nos missions nous ont permis de remonter jusqu'à l'origine du peuple wayana dans les monts TumucHumac (Figure 3), et de décrire la descente progressive du fleuve Maroni par le Litani (Aletani), qui forme la frontière avec le Suriname ${ }^{7}$. 


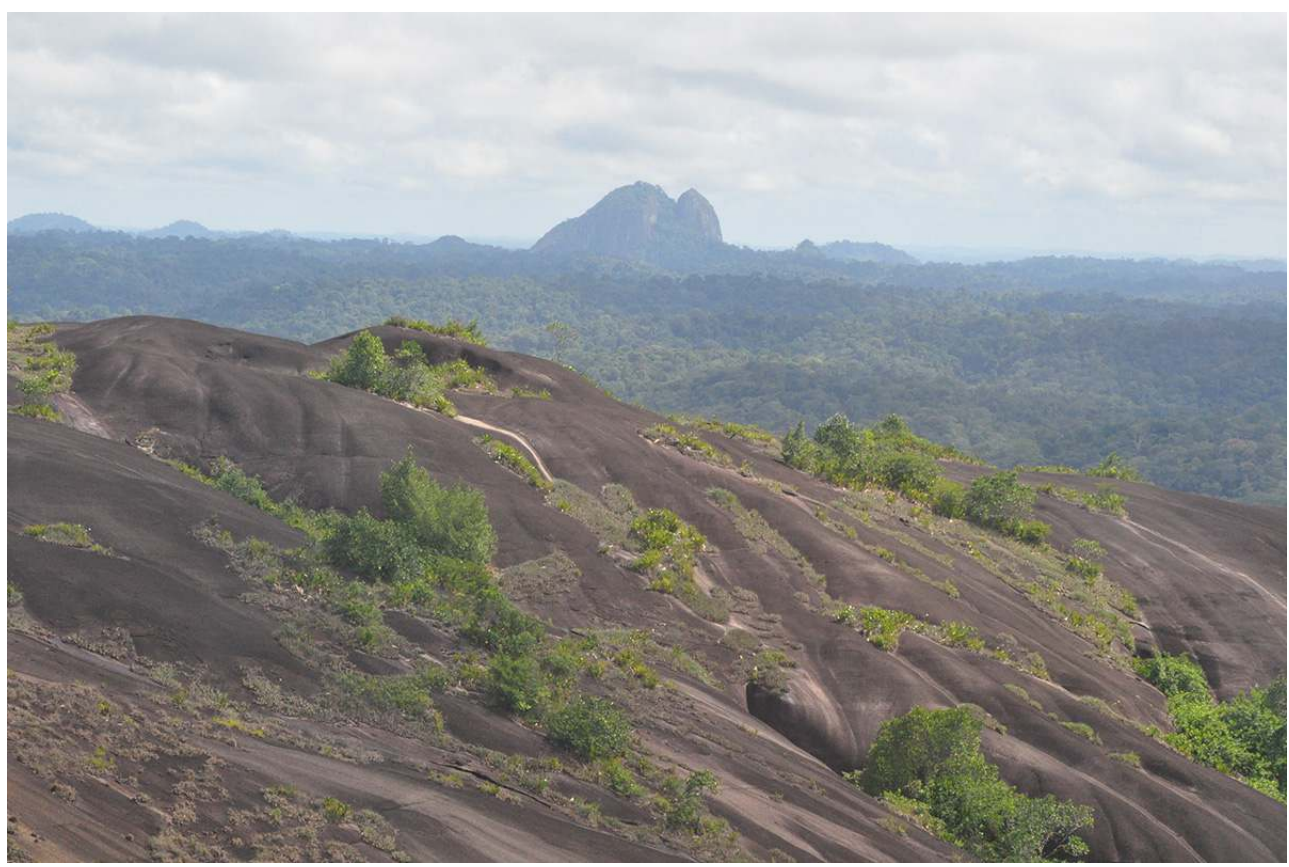

Crédit M. Fleury

21 Nous allons citer la liste de tous les toponymes relevés en suivant un ordre chronologique, depuis les temps des origines à partir des Tumuc-Humac au sud jusqu'au bas-Litani, actuellement habité, au nord. Pour chacun d'entre eux, lorsque cela est possible, nous avons consigné les événements, interprétations et observations recueillis pendant le travail de terrain de cartographie participative. Le lecteur pourra situer les toponymes à l'aide des cartes résultant de notre travail : la carte du début de la conquête du Litani (Figure 4), la carte générale des anciens lieux de vie, les cartes détaillées des anciens lieux de vie et toponymes (Figure 5, Figure 6, Figure 7, Figure 8 et Figure 9), et la figure 10 concernant la guerre avec les Taïla (Kali'na) au XIX ${ }^{\mathrm{e}}$ siècle. 
Figure 4 : Début de la conquête du Litani (fin du XIXe siècle)

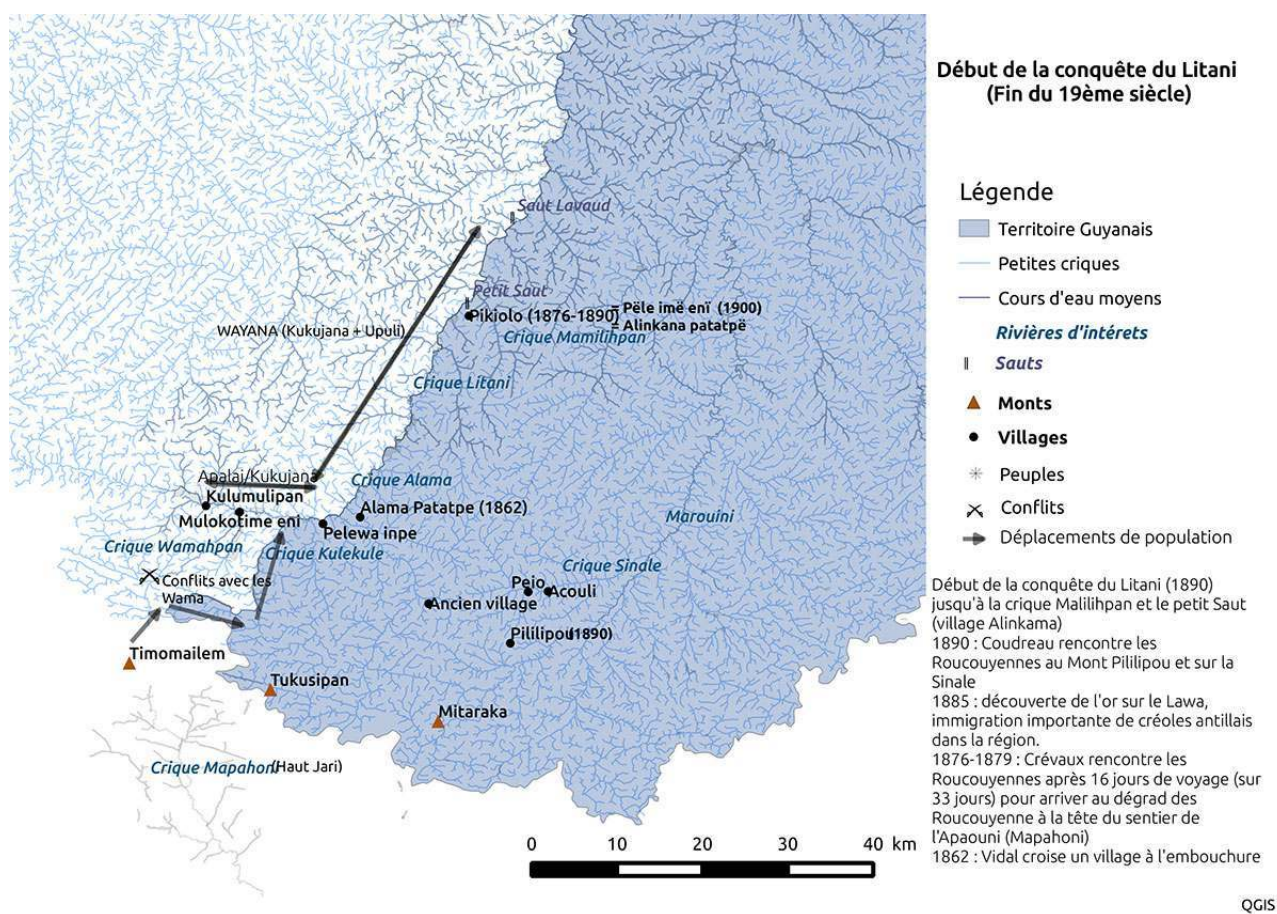

Figure 5 : Carte des anciens lieux de vie sur l'Aletani (Litani)

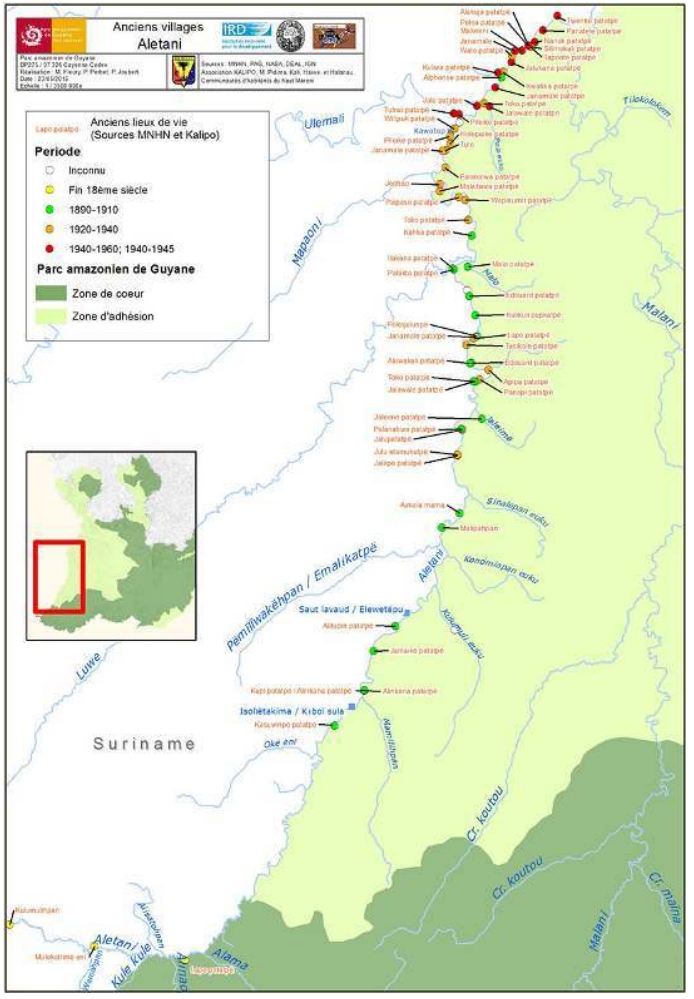


Figure 6 : Carte de la toponymie et des anciens villages sur l'Aletani (Litani) : partie 1 (sud : haut Litani)

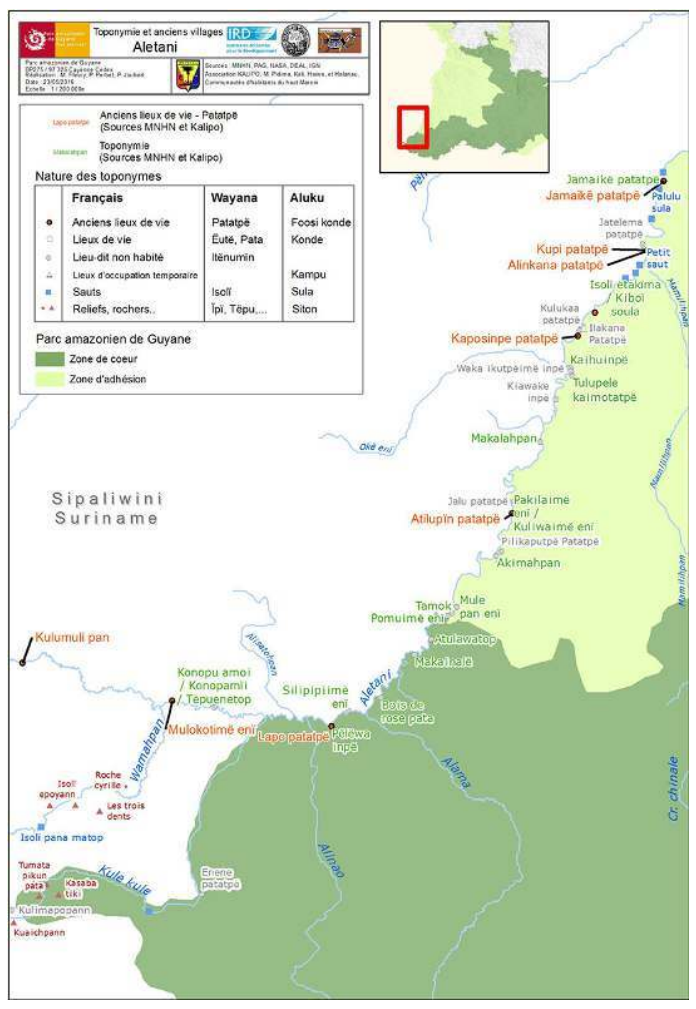

Figure 7 : Carte de la toponymie et des anciens villages sur l'Aletani (Litani) : partie 2 (moyen haut Litani)

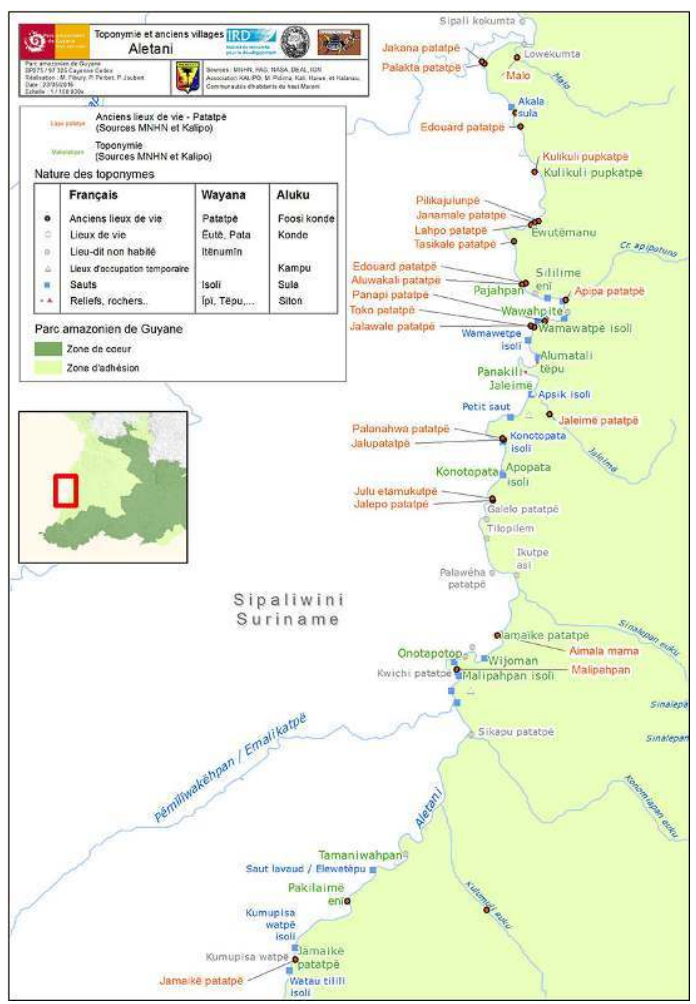


Figure 8 : Carte de la toponymie et des anciens villages sur l'Aletani (Litani) : partie 3 (moyen bas Litani)

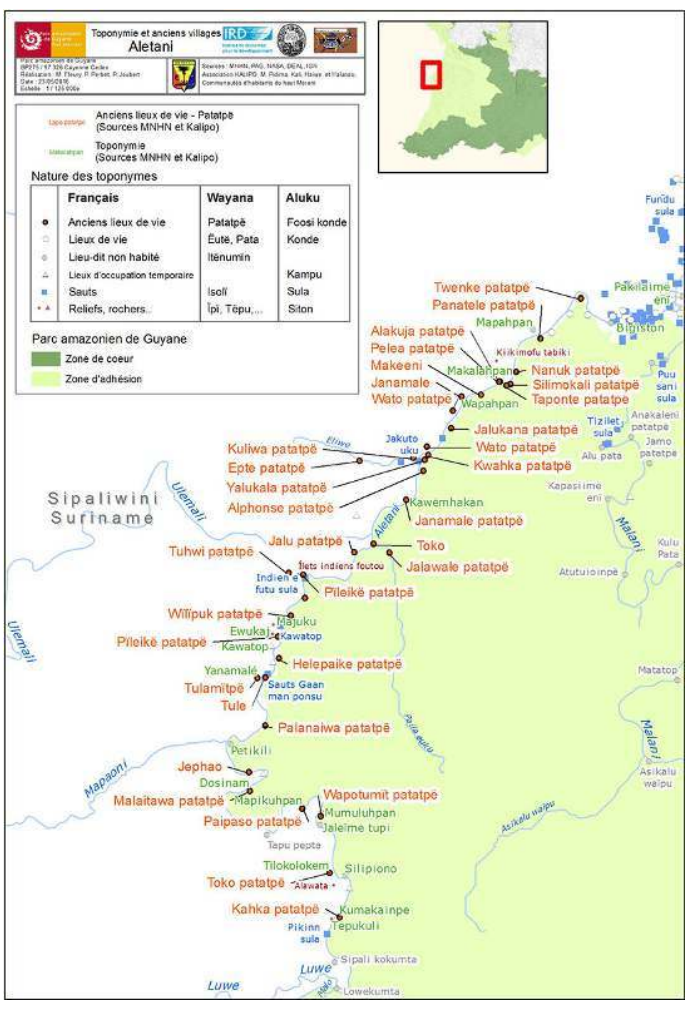

Figure 9 : Carte de la toponymie et des anciens villages sur l'Aletani (Litani) : partie 4 (bas Litani : région d'Antécume pata)

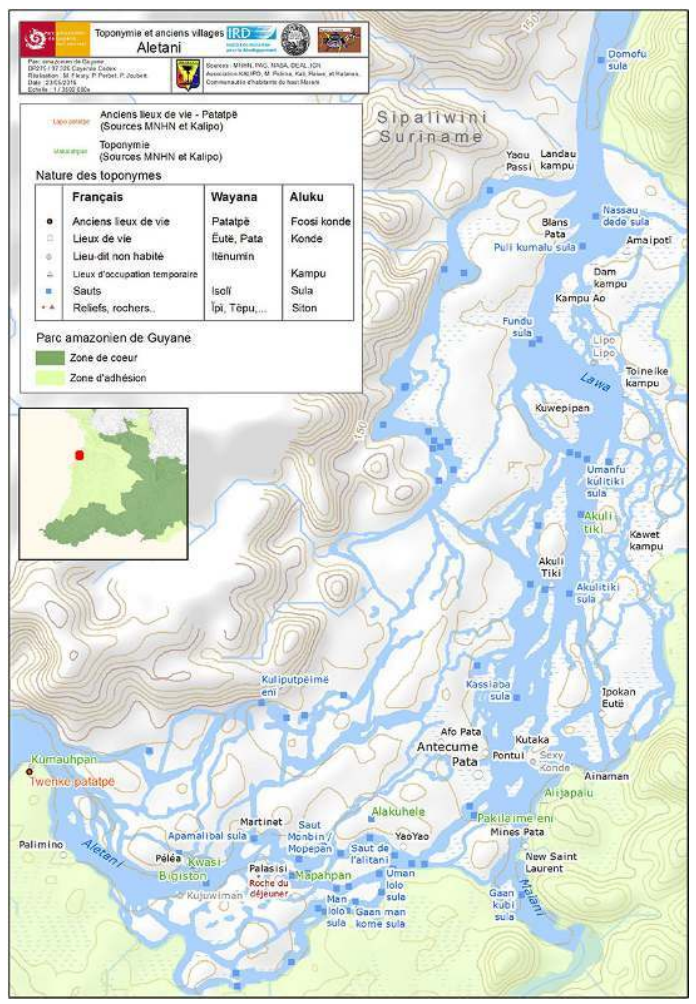


Figure 10 : La guerre des Taïla (Kali'na) contre les Tilïyo/Kukujana (vers 1775) sur le Litani

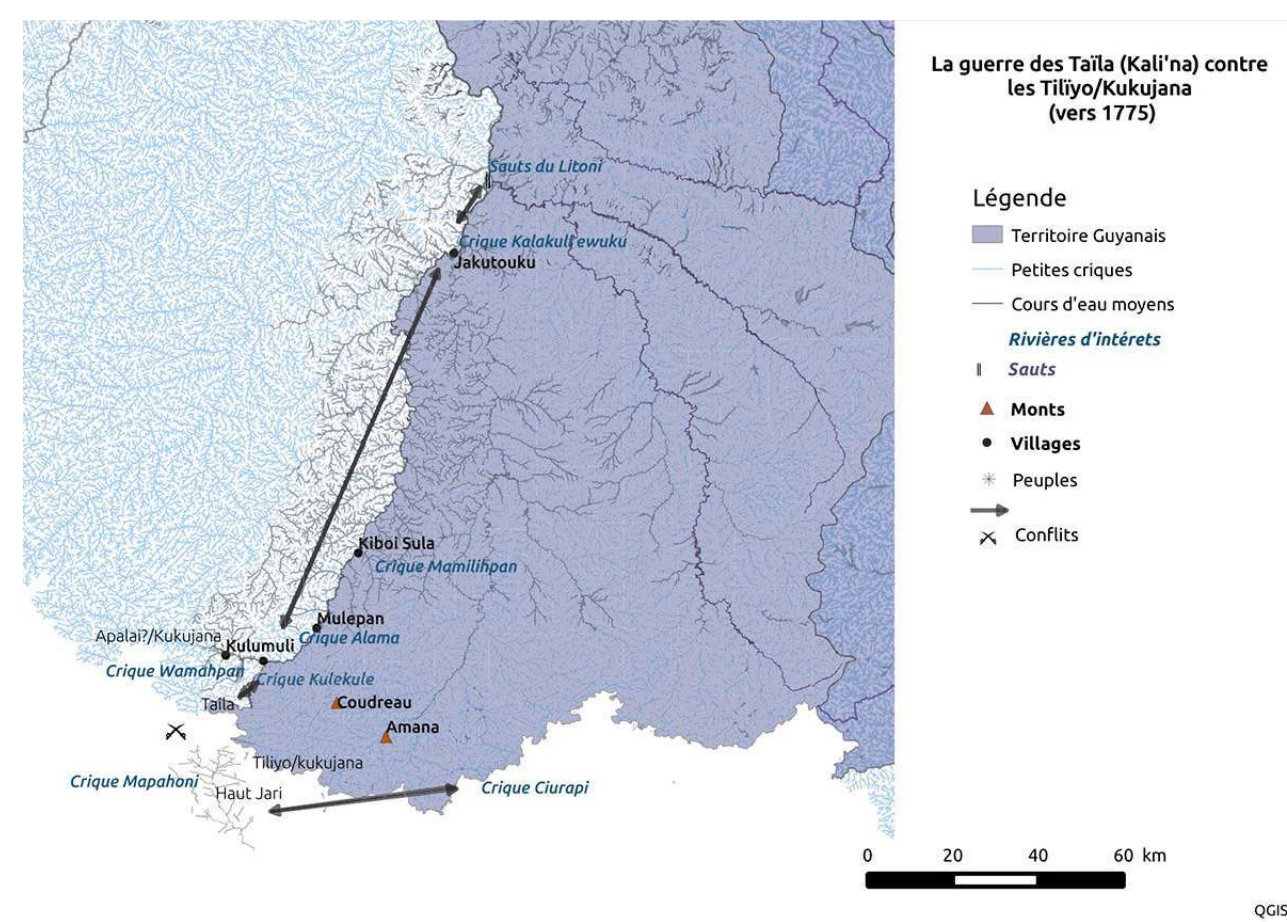

\section{Du sud au nord : toponymes et anciens lieux de vie}

1 - Tïmomailem : ce nom ${ }^{8}$ viendrait de imomasi ou momasi qui signifie la «jupette du tukusipan ». En effet la montagne ressemble à un tukusipan ${ }^{9}$ avec sa jupette (la base du toit constituée de feuilles de palmier) avant qu'on ne la coupe.

Situé entre les sources des criques Wamahpan et Mapahoni, au Brésil, cet inselberg est un lieu stratégique qui fait le lien entre les deux versants des Tumuc-Humac. Il se situe à miparcours sur le chemin des Amérindiens qui franchit la ligne de partage des eaux.

Dans la mythologie wayana, c'est là que s'est déroulé l'exploit de Sikëpuli (autre nom de Mopo, l'ami de Wapotoli, émanation du créateur qui maitrise la foudre) : Sikëpuli qui a hérité du casse-tête faiseur de foudre de Wapotoli, va y vaincre les Pijanakoto ${ }^{10}$ (Indiens sauvages qui vivaient dans des rochers ${ }^{11}$, constituant leurs maisons ${ }^{12}$. C'est après cet épisode que peut commencer la paix, car les Pijanakoto étaient les derniers ennemis à abattre par Kailawa. Comme les enfants ont mal attaché le casse-tête de Sikëpuli dans la rivière, celui-ci s'est échappé en se transformant en gymnote électrique ${ }^{13}$. Sikëpuli, de rage, abandonne les humains en retournant au ciel dans un éclair de foudre. Kailawa les abandonne à son tour : puissant chamane, il ne meurt pas, mais disparaît. Les Hommes désignent alors à sa succession un des ses fils adoptifs, d'origine Upului, comme le « nouveau Kailawa », mais celui-ci ne veut plus faire la guerre : Il désire la paix (Chapuis \& Rivière $2003: 729,741$ ). Les différents peuples vont alors se partager les rivières et c'est le début de la conquête du haut Maroni par les Wayana.

2 - Kulimapohpan ${ }^{14}$ : inselberg correspondant au point actuel de trijonction entre les trois pays : Brésil, Suriname et Guyane française.

3 - Kulumulihpan (= Kulumuli inpë $\left.{ }^{15}\right)$ : c'est l'emplacement du premier village ${ }^{16}$, le « lieu des bambous » (kulumuli/bambou). D’après Pidima, ce village, placé derrière la colline 
puisqu'on ne faisait pas encore les villages au bord des rivières, était peuplé uniquement d'hommes, de guerriers. Les femmes n'avaient pas le droit d'y accéder si elles avaient leurs règles ${ }^{17}$ ou étaient enceintes. Les enfants non plus ne pouvaient pas y résider. Des bambous avaient été plantés là pour la confection des flèches et pointes de flèches d'autant que ce bambou est venimeux et provoque des hémorragies ${ }^{18}$. Toujours, d'après Pidima, ce n'étaient pas des Wayana qui vivaient là aux temps anciens, mais des Apalaï. Ils n'avaient pas de couteaux, seulement des dents de félins. Ils cassaient les arbres pour faire des layons qui suivaient la rivière. Ces chemins étaient très longs, et parfois mal entretenus. Les Kukujana ${ }^{19}$ s'y rendirent et s'installèrent avec eux. C'était un village de réunions, très important, où l'on pouvait demander et obtenir l'autorisation de se déplacer sur le fleuve. "Ce pourrait être le fameux village appelé Etakpapïtpë (le partage), ou bien Ehenokïtpë (l'envoi) $»^{20}$ (Pidima, 2013).

D'après Alahu (2012), c'est là que vivaient les Pailaimë (« les arcs géants », paila/arc ou bois d'arc ${ }^{21}$; imë/géant) : le nom d'une ethnie avec lesquels les ancêtres des Wayana échangeaient les pointes de flèches en bambou (kulumuli).

Ce village, qui est le plus proche des sources du Litani est toujours désigné comme «le premier village ». Il se situe en amont de la crique Wamahpan, donc en amont des chemins des Wayana, pour atteindre le haut Jari au Brésil.

4 - Wamahpan «lieu des Wama ${ }^{22}$ ». C'était une crique habitée par les Indiens Wama, " Amérindiens féroces et ennemis des Wayana » (Pidima, 2013). On les appelait Wama, car ils faisaient leurs flèches avec de l'arouman (wama en wayana).

« Là-bas à Wamahpan, il y avait toujours la guerre. Ils rentraient discrètement dans le village, et ils tuaient tous les gens. On a fait la guerre avec eux durant de nombreuses années. C'était vraiment un lieu de tuerie. Même assez récemment, ils ont attaqué Janamale ${ }^{23}$, mais il avait déjà un fusil, il leur a tiré dessus.

À l'époque ancienne, les Wayana n'avaient pas de flèches, ils se battaient seulement avec des massues. Les Wama eux pouvaient tirer de loin » (Alahu ${ }^{24}$, novembre 2012) 25 .

On trouve sur cette crique l'ancien village d'Alawe (descendant du peuple Apalai de Kulumulihpan).

"Alawe avait fait son village sur la crique Wamahpan. Il se trouvait au premier saut: Il y a une grande cascade. En amont au sommet de la cascade $(300 \mathrm{~m})$, il y avait le village d'Awale. Au pied, il y a les traces des indiens Oyaricoulets : ce sont des pierres empilées ${ }^{26}$, des pierres posées en forme triangulaire, du plus gros jusqu'au plus petit » (Pidima, 2013).

5 - Mulokotïimë enï lieu-dit « le trou du Mulokot ${ }^{27}$ géant ». Selon Pidima c'est en ce lieu, qu'un jeune Apalai du village de Kulumulihpan a été tué par un monstre aquatique :

"L'Ancien a dit qu'il y a un jeune qui est parti au village de Kulumuli inpë ${ }^{28}$ pour rencontrer le Vieux ${ }^{29}$ et faire un village à l'embouchure de la Wamahpan ${ }^{30}$, car ils en avaient marre de manger toujours la même sorte de poisson. Peut-être voulait-il manger du coumarou? La mère du garçon s'appelait Mawahalepo; Elle a dit à son fils qu'elle avait vu un ipo ${ }^{31}$ à cette embouchure de Wamahpan. "Je l'ai vu pendant la nuit, c'était comme un petit poisson avec une dorsale en forme de flèche, qui nageait parfaitement bien. Ils se sont demandé quelle espèce était ce poisson. Ils l'ont appelé Mulokotiïmë. Pourtant tout était tranquille. Peut-être qu'on ne connaissait pas les poissons de la grande rivière à l'époque? Quelque temps plus tard, ils étaient bien installés, ils mangeaient bien, ils vivaient là. Quelqu'un est allé faire une nivrée, quand ils ont ramassé le poisson, ils ont vu la même espèce dans la forêt. Ils se sont demandé, «comment ce poisson est arrivé là? " il y avait un Mulokotïimë dans la mare ? Comment avait il pu arriver là ? Là-bas, c'est leur 
milieu, c'est pourquoi on l'appelle Mulokotïmë enï. Effectivement, les Wayana ont vu les Mulokotiïmë, quand ils passaient la nuit là-bas, lors d'un déplacement, mais ils n'y touchaient pas, car ils savaient qu'ils avaient déjà tué un homme » (Pidima, 2013).

Selon Ëputu (Chapuis 2007 : 150), il y avait un village Taïla (Kali'na) ${ }^{32}$ à Mulokotïmë enï ${ }^{33}$. Les Wayanahle (Kukujana) et leur chef Tapanawale ont vécu avec eux dans ce village jusqu'à l'assassinat de celui-ci, ce qui entraîna une guerre sans pitié avec une alliance avec tous les autres peuples amis, jusqu'à disparition totale des Taïla du haut Maroni.

\section{6 - Konopamïi (Konopu amoï en aluku) (Figure 11)}

«Mon grand-père qui s'appelait Alawe, est parti du village vers l'inselberg peutêtre à la chasse avec d'autres hommes. Ce sont eux qui ont découvert l'inselberg Konopamiii. Ils étaient avec un indien Wai ${ }^{34}$. L'ancien nom était Tëpuenetop (« lieu où l'on voit l'inselberg ", tëpu: rocher, inselberg / enetop: vue, vision). On se demande pourquoi on l'a ensuite appelé Konopamiï, parce que tout le monde l'appelait Tëpuenetop. Peut-être cela vient-il d'une autre langue?» (Pidima, 2013).

En effet, ce nom konopu amoï signifie «bouton joli » (konopu/bouton; a moï/c'est joli) en langue aluku ${ }^{35}$ (Crevaux 1883: 112). C'est ce nom d'origine aluku et dont l'écriture a été modifiée par le wayana, qui est resté dans la mémoire collective.

31 Il avait également été baptisé "piton Vidal » par Crevaux (1883) en hommage à Vidal, lieutenant de la commission franco-hollandaise chargée de reconnaître le principal affluent du Maroni pour déterminer la frontière officielle entre les Guyanes hollandaise et française, et qui stoppa sa mission à cet inselberg et l'escalada en 1861. Mais cette dénomination n'est pas restée, sauf sur certaines anciennes cartes.

Figure 11 : KONOPOAMIil : lieu où l'on aperçoit l'inselberg à partir du Litani

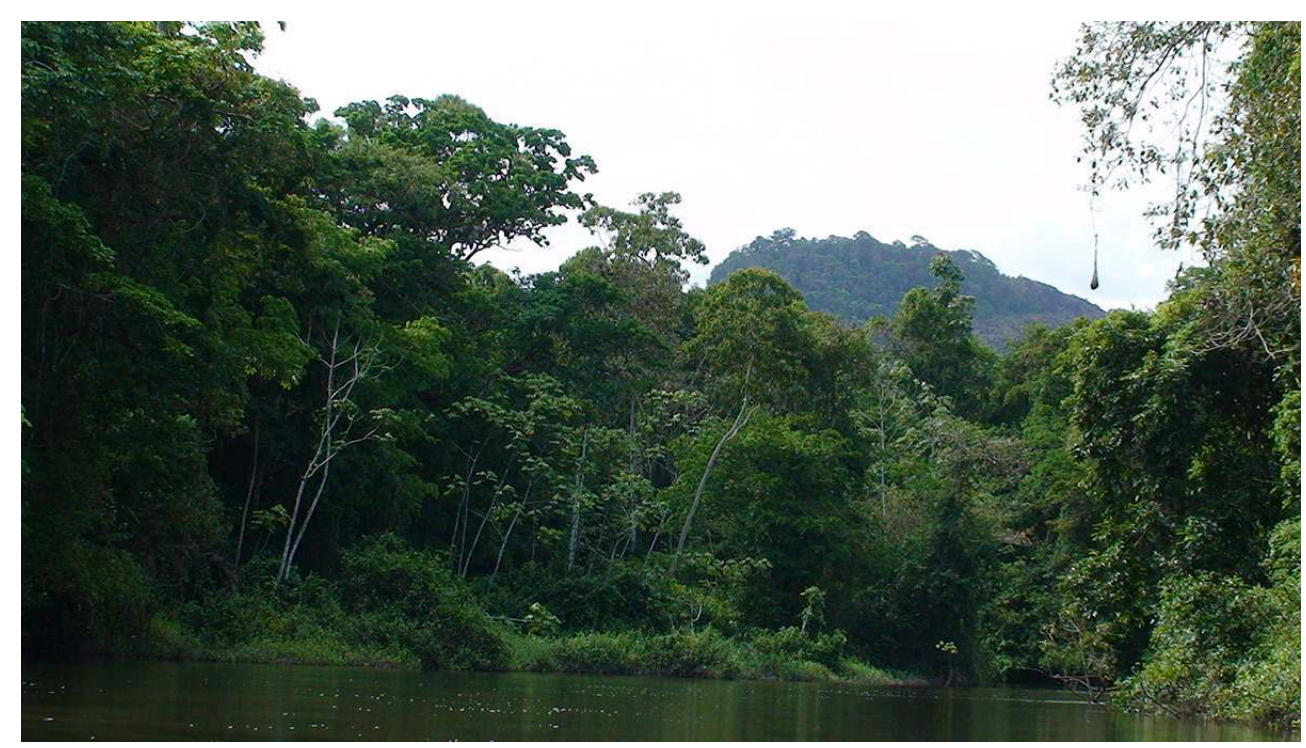

Cliché M. Fleury

327 - Kulekule : c'est la crique de la paix (kule/paix).

«Kailawa qui avait déjà fait des déplacements un peu partout, a formé des groupes d'hommes pour trouver des emplacements favorables, des terrains propices. C'est comme cela qu'ils ont trouvé les rivières et les cours d'eau. Un groupe a été envoyé de ce côté ci. Après une journée complète de marche, 6 h environ, ils ont vu le fleuve Aletani. Ils ont découvert ce fleuve. Ces gens là s'appelaient Kuletikahamo ("les 
gens de la paix"). Ils sont arrivés par la Kulukule. À leur retour, ils ont dit qu'ils ont rencontré les Kukujana et les gens de Kulumulihpan » (Pidima, 2013).

C'est cette crique qui fait actuellement frontière avec le Suriname au sud. C'est aussi un des chemins wayana qui permettait de rejoindre les autres villages wayana du Jari. La crique Wamahpan est un chemin plus court, mais la crique était occupée à l'époque par les Amérindiens ennemis Wama.

8 - Alisatohpan : crique sur la rive surinamienne.

9 - Alinao : crique sur la rive française.

10 - Pëlewa inpë lieu-dit « endroit de Pëlewa ». Lapo patatpë (ancien village de Lapo).

«La-bas, il y avait une jeune femme adolescente qui s'appelait Pëlewa. Elle était gaie, mais intimidée par les Tepiem ${ }^{36}$ qui étaient au dégrad. Alors, elle est partie dans la crique, sous les yeux des Tepiem. C'était le soir, vers 17h peut-être. Les Tepiem étaient allés se laver avant la nuit pour remonter au centre du village, près $\mathrm{du}$ feu. À ce moment la jeune femme arrive avec une calebasse d'eau. Elle jette la calebasse, et se jette elle-même à l'eau. On dit qu'un ipo l'a dévorée. Il n'y a que les poumons de la fille qui sont remontés à la surface. La fête a été annulée, puis on a abandonné le village. Le dégrad était en rochers, et après il y avait un bassin. Pas très idéal, car on dit que les bassins sont les trous pour les ipo. Et pourtant ce n'était pas très profond. Ce n'était pas un endroit qui faisait peur. La fille s'appelait Pëlewa; c'était une Wayana. Ensuite, comme c'était la fête au village, les Momai sont venus du village de Kulumuli inpë. Les momaï étaient les invités qui venaient tresser les vanneries pour le maraké. Ils avaient déjà mis le cachiri dans les maipuri ${ }^{37}$. Comme on ne les voyait pas revenir, les gens de Kulumulihpan sont venus à leur rencontre, et ont vu qu'ils étaient en deuil. Ils ont aussi vu l'ipo, qui était revenu à la surface. Ils l'ont attrapé et ils l'ont mangé : c'était un très gros poisson aimara : aimalaimë.

Donc les gens de kulumuli inpë, ont mangé l'aïmara géant, car ils étaient rentrés le soir au village, mais ils n'ont pas dit que c'était l'aimara qui avait tué la jeune fille. Ils ont partagé l'aimara avec les gens du village. Tous les gens ont mangé la bête en entier : les écailles et les os aussi, pour venger la fille. C'était une sorte d'aïmara, mais aussi d'anaconda. À la suite de cela, quelques personnes sont tombées malades, ils ont eu des allergies. Cela, je ne l'ai pas vu, mais c'est mon père qui me l'a raconté et c'est le grand-père de mon père qui l'a raconté aussi, donc c'est très ancien. Voilà c'était l'histoire de Pëlewa inpë » (Pidima, 2013).

11 - Silipipiimë enï, lieu-dit « le trou du monstre kikiwi géant » (silipipi/oiseau kikiwi ${ }^{38}$; imë/géant; enï/trou)

12 - Alama ${ }^{39}$, crique dont le nom est l'éponyme du groupe des Alamajana ${ }^{40}$, qui selon Chapuis (2007 : 31) sont un des groupes fondateurs des Tilïyo, alliés avec les Kukujana et qui combattaient avec eux (Ibid : 49).

Il y avait un village très ancien sur la crique Alama : Alama patatpë (1890). Pidima raconte que c'est un des premiers villages du côté français de la ligne des partages des eaux, on y trouvait des bananiers sauvages ${ }^{41}$.

«Les gens se sont croisés aux Tumuc-Humac, comme à Alama patatpë : les gens du Jari et de tous côtés venaient s'installer là-bas ». (Pidima, août 2015).

39 Ce témoignage est confirmé par Vidal (1861) qui note la présence d'un village à l'embouchure de la crique Alama, village qui aurait été créé pour faciliter les relations de commerce avec les Boni, et qui fait le lien avec les villages du Jari. Notons aussi le signalement par Coudreau en 1890, d'un village abandonné, plus en amont sur la crique, à deux jours de marche de l'embouchure.

Aux environs de la source de cette crique Alama, dans les monts Mitaraka, un des auteurs 
${ }^{42}$ a trouvé accidentellement des tessons de céramique, qui ont pu être datés grâce à des restes de nourriture carbonisés : ils remontent le plus probablement du début du XIX ${ }^{\mathrm{e}}$ siècle. Étant donné la richesse de la zone en tessons de céramique, il semble y avoir eu plusieurs lieux d'habitat dans ce secteur se situant à la source de la crique Alama, dans le massif des Mitaraka, ce qui correspond, d'après l'histoire orale, au lieu de l'origine des Wayana (Chapuis \& Rivière 2003, Chapuis 2007).

13 - Atula watop, lieu-dit «la danse des martins pêcheurs » (atula ${ }^{43} /$ martin pêcheur à ventre roux ; watop/danse, fête) :

«c'est là où ils creusaient pour attraper les martins pêcheurs. Il y avait un campement sur la colline, ce n'était pas un vrai village ». (Pidima, 2013)

$41 \quad 14$ - Bois de rose pata, lieu de l'ancienne usine de bois de rose. Dans les années 1930, les Français y avaient installé une usine pour extraire l'huile essentielle de bois de rose ${ }^{44}$. 15 - Sihnatëhpan, crique dite «le lieu des lianes» (sihnat/liane; pan/lieu), car il y a beaucoup de lianes.

16 - Makainnalë, endroit où mangeaient les Taïla (Kali'na). À l'époque, ils étaient amis avec les Wayana, et parfois mangeaient ensemble.

18 - Tamok, lieu-dit des Tamok :

«C'est le trou des Tamok. Les Tamok c'était des êtres de toutes sortes de taille, des petits, des grands. Ils aimaient chanter. Ils portaient des graines de Kawai. Ils avaient tous cet instrument avec lequel ils faisaient de la musique en marchant. À cet endroit-là, il y avait des Tamok. Les chasseurs ont fait des huttes pour se cacher. Un jour un chasseur ainsi caché dans sa hutte, a vu un petit Tamok arriver : il l'a flèché. Mon père me disait de ne jamais envoyer les enfants de ce côté, car on pense qu'il y a toujours des Tamok. Ils portent des masques en okalat ${ }^{45}$, des plumes et une espèce d'arme (tain) comme un fouet » (Halanau, août 2013).

Tamok $^{46}$ est aussi le nom d'un masque (Figure 12) porté pour la danse rituelle Pono, précisément avec des fouets, décrite par Coudreau en 1873, mais actuellement disparue. Les masques Tamok continuent d'être fabriqués pour la vente par quelques personnes: autour d'une structure en arouman, est fixé un visage en cire teint avec des motifs, le reste du masque est constitué de lanières tirées de l'écorce de l'arbre okalat, teinte en noir, par imprégnation dans la boue (Van Velthem 2003, Duin 2014, Fleury sous presse). 
Figure 12 : Masque Tamok actuellement réalisé pour la vente

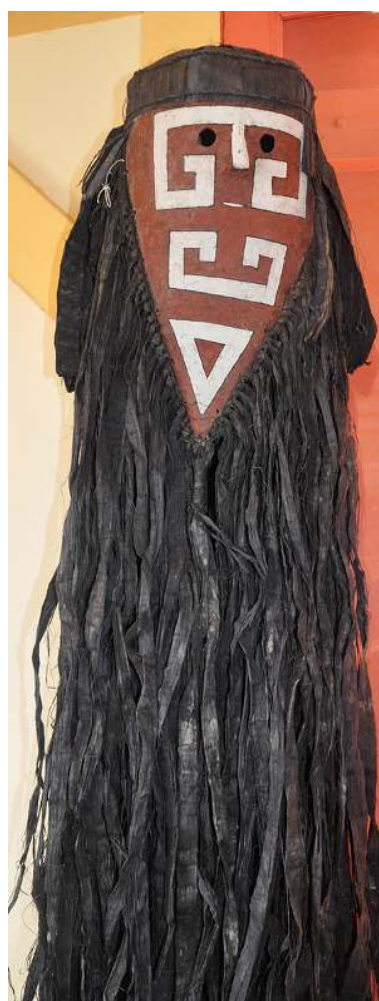

Cliché M. Fleury

19 - Mulepan enï, lieu-dit « le trou de l'emplacement du bébé » (mule/bébé ; pan/lieu ; enï/trou). Voici son histoire ${ }^{47}$ :

"C'était une femme stérile qui ne faisait pas d'enfant. Un jour elle passe sur ce rocher, et voit un bébé qui pleure. Elle le prend, et lui donne le sein. Mais le bébé (qui en fait était un monstre aquatique) lui mord le sein et retourne à l'eau. Ensuite le sang a coulé, beaucoup... et elle en est morte. C'est comme cela qu'on connait cet endroit » (Halanau, août 2013).

20 - Akimahpan, « le lieu d'Akima ». Ce jeune homme Akima s'est fait manger ici par un monstre aquatique : il avait voulu flécher un petit poisson, mais celui-ci était un esprit de l'eau, et l'a dévoré.

21 - Kulimawuimë enï, lieu-dit « le trou du pak géant » (Kulimawu/paca ; imë/géant; enï/trou). Il y avait un village non loin sur l'île : Watauhahkatop (« le lieu où l'on a salé le coumarou ») : c'était le village d'Alitupïn (Alitupïn patatpë).

22 - Makalahpan, lieu-dit des arbres makala ${ }^{48}$ qui donnent des fruits comestibles. C'est un beau lieu pour les campements, avec des roches plates sur la berge.

\section{3 - Tulupele kaimotatpë, « l'endroit où attaquait Tulupele ${ }^{49}$ » :}

"Quand ils ont découvert le fleuve, ils ont voulu le descendre, mais il y avait Tulupele qui barrait la route. En aval de Hokeimë il y avait Tulupule inpë, le trou du Tulupele, là où l'on voit la colline. C'est là que les gens ont créé des pirogues avec les Indiens de Kulumuli inpë, en écorce de mëpu ${ }^{50}$ (courbaril). Mais beaucoup descendaient et ne revenaient jamais. Kailawa s'est interrogé. Beaucoup de pirogues partaient, mais aucune ne revenait. Par la suite, ils ont découvert qu'il y avait un monstre. Avec l'aide des Kukujana, les Hommes-Lucioles qui plongeaient dans l'eau et voyaient la nuit, Kailawa ${ }^{51}$ a tué Tulupele » (Pidima, août 2015). 
Mythe de Tulupele ${ }^{52}: \mathrm{Ou}$ « comment les motifs de la vannerie sont venus aux Upului et aux Apalai » Conte recueilli auprès de Sintaman et traduit par son petit fils Waiso Aloïké en 1998

« Tout a commencé par un habitant du village, qui a coupé la queue d'un lézard et pris un arbuste qui s'appelle yawilëkë ${ }^{53}$, et un autre awalepokan ${ }^{5455}$. C'est avec leurs feuilles qu'il ventila la queue du lézard. Pendant qu'il ventilait, la queue bougea et ensuite devint un animal. L'homme devint le maître de l'animal qui s'appellait Tulupele. L'animal ressemblait à un jaguar mais avec une queue de chenille et différents dessins dessus. La bête grandit, et son maître la laissa aller dans la forêt. Plusieurs années passèrent, l'animal était devenu l'ennemi des gens, que ce soit les Upului $^{56}$, ou les Apalai ${ }^{57}$. L'animal habitait sur la colline; en bas de la colline se trouvait le fleuve où les gens passaient. Ils étaient toujours victimes de la bête. Lorsqu'un canot passait, un oiseau qu'on appelle alalawa $\left(\mathrm{Ara} \mathrm{bleu}^{58}\right)$ criait et alertait l'animal. Lui se réveillait, descendait de la colline et plongeait dans l'eau ; il retournait le canot, et tuait les passagers. Les Upului descendaient chez les Apalai, mais disparaissaient et vice-versa : c'était la même chose pour les Apalai qui montaient chez les Upului, ils ne revenaient plus jamais au village. Un jour, les gens partirent à la recherche des gens disparus. Ils étaient plusieurs canots et ainsi virent le premier canot attaqué par Tulupele, et ils firent demi-tour. De retour au village, ils firent une réunion entre hommes, et expliquèrent aux villageois ce qu'étaient devenus les disparus. Le lendemain, ils installèrent des pièges et coupèrent des bois qu'ils attachèrent à une hauteur permettant à la bête de passer en dessous. Quand ils eurent terminé tous les pièges, une personne handicapée servant d'appât pour l'animal, se mit dans le canot et remonta le fleuve à la pagaie, jusqu'à ce qu'il entende le signal de l'oiseau. L'animal ne sachant rien, sortit de sa cachette et descendit la colline, au bord du fleuve. Les chasseurs, installés en haut des arbres, commencèrent à flécher l'animal, et celui-ci ayant reçu plein de flèches sur le corps, plongea dans l'eau et mourut... les chasseurs étaient à la fois des Apalai et des Upului. C'est à ce moment-là qu'ils firent la paix. Ils partagèrent alors la peau de l'animal. Les Upului prirent la partie droite et les Apalai l'autre partie, gauche. Ces sont les dessins de la peau de l'animal qui ont été recopiés jusqu'à aujourd'hui par les gens qui savent faire de la vannerie, et même les femmes qui font des ceintures de perles. Et c'est pour cela que les Apalai aussi savent tresser les vanneries en recopiant les dessins pris sur l'animal tué ».

24 - Oke enï, nom d'une crique sur la rive surinamienne (okë/boisson; enï/trou)

25 - Kasuwinpe patatpë (années 1890-1900) : ancien village de Kasuwinpe : l'arrière grand-père de Kali a vécu là.

26 - Isolï ëtakïma = Kiboi sula, c'est le "premier saut " (le saut de Kiboi en aluku). Notons que les Wayana de l'époque n'étaient pas de grands navigateurs. Ils avaient l'habitude de vivre en forêt, et ne connaissaient que les canots en écorce. Le passage des sauts était donc un obstacle important sur les rivières.

27 - Mamilïhpan, crique « lieu des lianes franches » (mamilïhle ${ }^{59} /$ liane franche ; pan/ lieu) 
28 - Pëleimë enï ${ }^{60}$, « le trou du poisson-roche géant » = Alinkana patatpë. Cela date du temps des grands-parents de Kali (années 1900). «C'est à l'embouchure de la crique Mamilihpan qu'Alinkana est descendu jusqu'au premier saut et a construit son village » (Pidima, 2013). C'est très certainement le village appelé Pikiolo par Coudreau (1893) et le village Roucouyenne que Crevaux croise lors de sa remontée du Litani jusqu'au TumucHumac.

C'est aussi le lieu de l'ancien village de Kupi : Kupi patatpë (années 1900-1910), qui était l'oncle de la femme de Twenke (la maman d'Amaïpoti).

29 - Palulu sula (en aluku) = paluluimë (en wayana), saut des balisiers (bananiers sauvages) :

« des gens ont coulé dans ce saut. Pidima nous raconte l'histoire de ce lieu : Un jour quelqu'un a vu un ipo, il le dit à son cousin «j'ai vu un ipo », mais celui-ci ne le croit pas. Le lendemain matin à $6 \mathrm{~h}$, il part à la pêche. Quand il arrive à cet endroit, il se demande si l'histoire est vraie ou pas... Il commence à pêcher, à flécher les coumarous. Puis il jette les appâts dans l'eau. Le poisson arrive vers l'appât. Il le flèche, et tout d'un coup, le poisson se débat dans l'eau. Le pêcheur veut aller ramasser sa flèche avec le coumarou. Quand il est à environ cinq mètres du poisson, celui se débat et entraîne le pêcheur sous l'eau. L'eau s'est soulevée très haut quelques secondes. Peu de temps après, les poumons du jeune homme sont remontés à la surface » (Pidima, 2013)

30 - Jamaikë patatpë, ancien village de Jamaikë (années 1900).

31 - Kumupisa watpë, lieu-dit «où on coupe les grappes de comou». C'est l'ancien village de Jamaikë, grand-père de Kali (Jamaikë patatpë) : (années 1900).

«Il y avait un chamane qui habitait là, quand il est mort, il ne voulait pas être enterré, il voulait rester dehors et avoir un palmier comou comme siège : on l'a donc assis sur la grappe de comou, et on a abandonné le village » (Kali 2015).

32 - Pakilaimë enï, lieu-dit « trou du pécari à collier géant ». Ancien village de Atilupïn ( Atilupïn patatpë), du temps des grands-parents de Kali (années 1900)

6133 - Elewetëpu = Saut Lavaud (Figure 13), saut de la " roche des ananas sauvages ${ }^{61}{ }$ ( elewe/ananas sauvage; tëpu/roche), dit aussi «Saut Lavaud», depuis que Jean Lavaud, fils du compagnon de route de Coudreau en 1893 et époux d'une Wayana est mort noyé dans le saut le 30 avril 1915, en rentrant d'un séjour avec son père dans la région du haut Jari (Hurault 1972). 


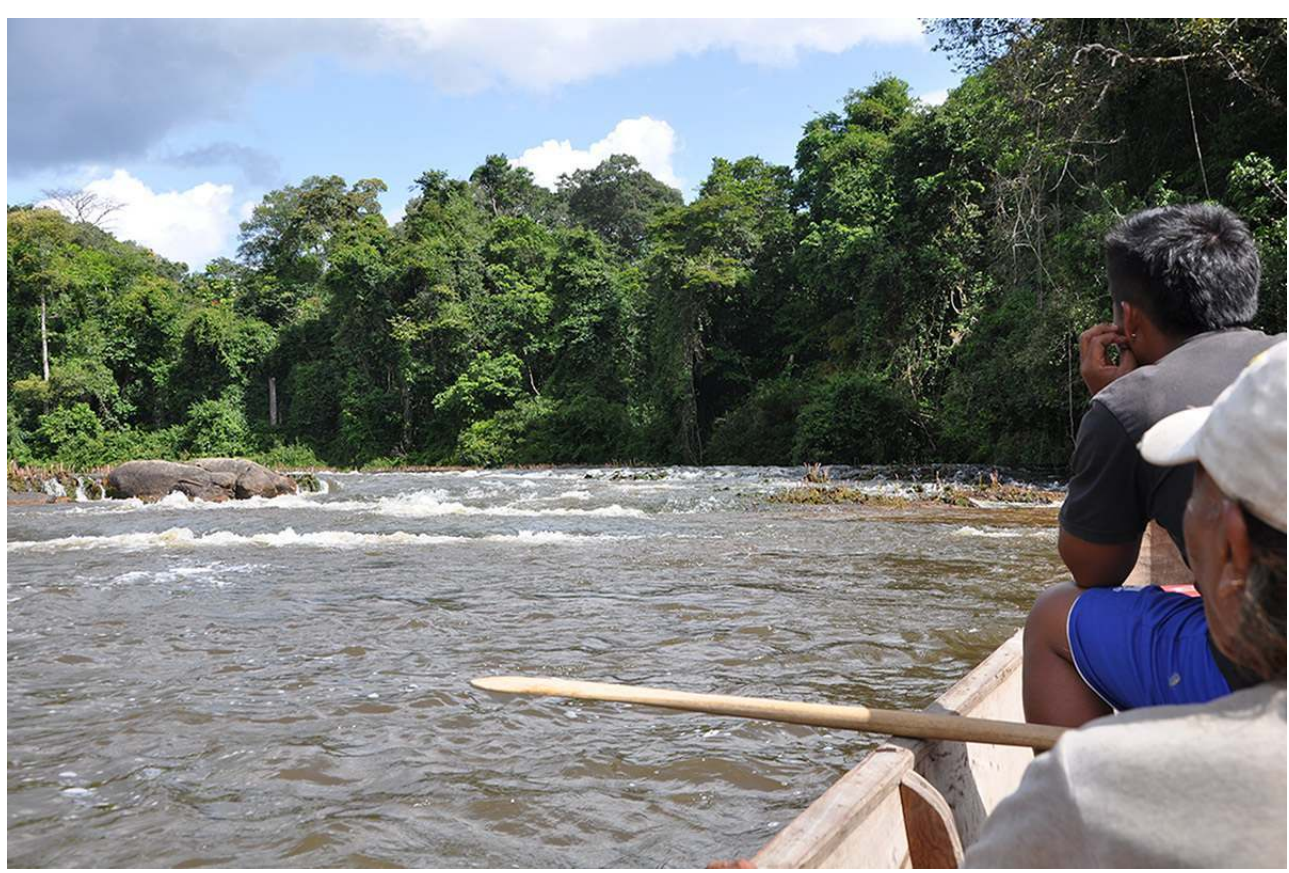

Cliché M. Fleury

34 - Kulumuli euku, «crique des bambous ». Il y avait un village sur la crique, mais son nom a été oublié.

35 - Tamaniwahpan, lieu-dit des tamaniwa ${ }^{62}$ (arbre donnant un fruit comestible).

36 - Emalikatpë. Autrefois il y avait beaucoup de wajalikule (Oyarikule) ou pijanakoto (êtres barbares vivant dans la forêt, très savants en magie, agressifs et sauvages, et qui vivent en bandes comme des animaux n'ayant pas de village) (Chapuis $2003: 203$ ).

On l'appelle aussi Pëmiliiwa këhpan, crique « où il y a beaucoup de fourmis rouges». En amont sur cette crique, il y a eu le village du grand-père de Pidima :

«Le père de Toko, Opomali, et Talihe, sont devenus les occupants de la crique des fourmis rouges. Il y avait beaucoup de village le long des criques. Ce sont eux, c'està-dire nos ancêtres, qui ont commencé à faire des villages le long de la rivière Aletani » (Pidima, 2013).

37 - Malipahpan, lieu-dit des palmiers maripa ${ }^{63}$. Il y avait le village de Kumalaikë: Kumalaikë patatpë (années 1900). C'était la famille de Twenke et Haiwe qui habitait là, et Halanau y a habité. C'était du temps des grands-parents de Kali.

38 - Onotapotop, lieu-dit « là où on écrase le roucou ${ }^{64}$ ». C'était là, sur la roche plate de Onotapotop, qu'allaient se préparer les Tepiem avant les danses du maraké pour écraser le roucou et s'en enduire le corps.

39 - Wijoman, lieu-dit « virages » La rivière fait beaucoup de méandres à cet endroit-là.

40 - Aimala mama, lieu-dit de l'aimara géant (toponyme aluku). Jamaikë patatpë (années 1900-1910) : c'est le lieu du premier village de Jamaikë (le grand-père de Kali). C'était aussi le village de Toko, grand père de Pidima, et ancien grand chamane.

41 - Crique (sans nom) : c'est un lieu tabou. "Cette crique n'a pas de nom et elle est interdite car il y a eu beaucoup de mort (cinq), certainement dus à un monstre aquatique (ipo) » (Pidima, 2013). 
42 - Jalepo patatpë (années 1920-1930), ancien village de Jalepo. C'était du temps des parents de nos accompagnateurs.

43 - Julu etamukutpë, lieu-dit du chablis de l'arbre julu ${ }^{65}$.

Il y avait là l'ancien village du chamane Jalu (Jalu patatpë). Le père de Pidima a connu cet endroit dans les années 1920.

44 - Konoto pata, lieu-dit «lieu des escargots d'eau ${ }^{66}$. Ce sont de gros escargots comestibles que les Wayana aiment consommer.

45 - Hapopata isoli, « saut Hapopata » (hapo/chapeau ; pata/endroit ; isolï/saut) : peutêtre avait-on oublié un chapeau dans ce saut?

46 - Palanahwa patatpë (années 1900). C'est l'ancien village du père de Ëputu qui s'appelait Palanahwa.

47 - Jaleimë patatpë = Wapotumït $^{67}$ patatpë (années 1900). C'est une crique avec d'anciens villages le long de la berge. On y fait fréquemment des campements encore actuellement.

48 - Alumatali tëpu, roche Alumatali (Figure 14). C'est une roche verticale au milieu de la rivière.

«On doit fermer les yeux, la première fois qu'on la voit. Sinon on attrape des champignons sur le corps. C'est un des chamanes qui a vu les esprits des rochers qui a conseillé cela. Il faut faire de même quand tu vois un inselberg pour la première fois, comme Tïmomailem ou Taluwakem. De plus, au retour, il faut faire un régime, ne pas manger n'importe quoi. C'est la tradition des rochers ${ }^{68} »$ (Pidima, 2013).

Figure 14 : Roche Alumatali

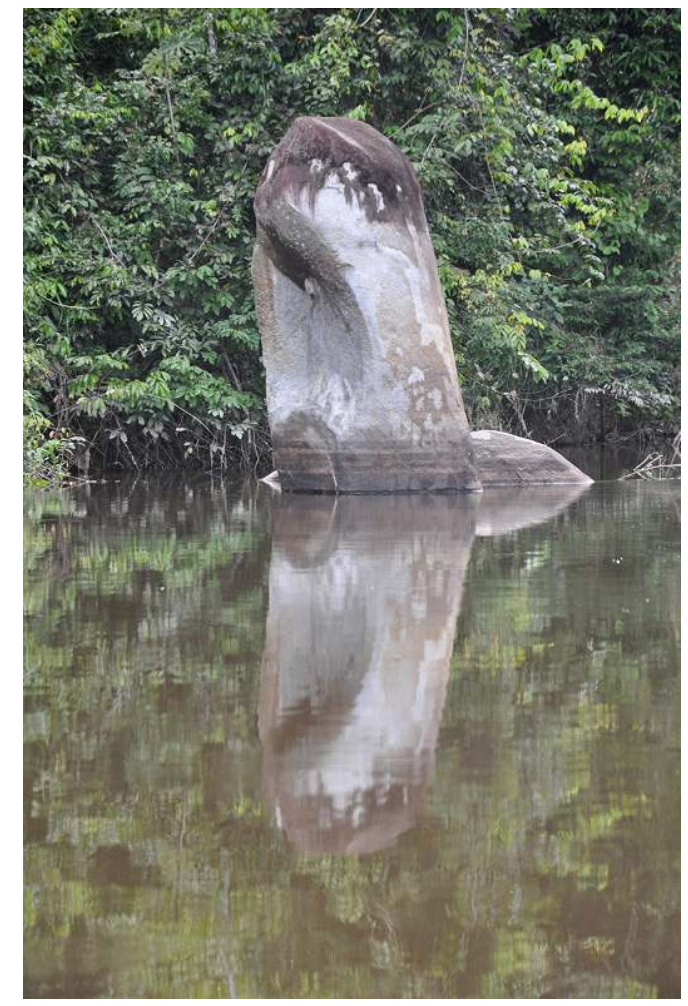

Cliché M. Fleury 
49 - Jalawale patatpë (années 1880-1900). Ancien village du temps des grands-parents de nos accompagnateurs.

50 - Toko patatpë (années 1880-1900). C'est un autre ancien village du grand-père de Pidima.

51 - Wama wetpë isolï, "saut où l'on a tué les Indiens Wama», lesquels étaient rappelons-le, des ennemis des Wayana, qui avaient des flèches en arouman (wama).

52 - Panapi patatpë (années 30-40). Ancien village de Panapi, le père de Pidima quand Pidima était enfant.

53 - Apipa tuna ${ }^{69}$, crique avec un ancien village : Apipa patatpë = Alawata patatpë (années 1930). Apipa, c'était son vrai nom, son surnom c'était Alawata (singe hurleur ${ }^{70}$ ). C'était du temps du père de Kali, Janamale, quand il avait 14-15 ans.

54 - Sililimë enï, lieu-dit du trou de l'oiseau Cotinga géant (sili ${ }^{71}$ : nom d'un oiseau qui fait silili quand il vole). Souvent appelé Cognat patatpë, c'est l'endroit où André Cognat ${ }^{72}$ voulait faire un nouveau village en 1972, mais les autres n'ont pas voulu le suivre, ils ont préféré rester à Antécume pata. Il n'y a donc jamais eu de village, seulement un abattis (André Cognat comm. pers.).

8355 - Pajahpan, lieu-dit « lieu des herbes » (paja/herbe), c'était une île couverte d'herbes. Il y avait le village d'Aluwakali (Aluwakali patatpë), et un village d'orpailleurs créoles : Edouard Patatpë (années 1890-1900). Les deux villages étaient côte à côte en face de l'île pajahpan. Cela date de l'époque des grands-parents de nos accompagnateurs les plus âgés, soit 1890-1900.

56 - Tasikale patatpë (années 1930-1940). Ancien village de Tasikale, l'ancêtre de Tasikale Alupki, co-auteur de cet article. Pidima et Kali l'ont connu quand ils étaient enfants. C'était un petit village, sans carbet communautaire tukusipan.

57 - Ëwutëmanu, lieu-dit. C'était le village de Lapo (Lapo patatpë) (années 1920). Il y avait un tukusipan.

58 - Janamale patatpë, ancien village de Janamale, père de Kali.

59 - Pilikajulunpë (années 1900). Village du père de Kali (Janamale), quand il était jeune (elle-même n'a pas connu).

B 60 - Kulikuli pupkatpë, lieu-dit « là ou on a coupé les pattes du perroquet ». C'est le nom $\mathrm{du}$ saut et de lîle, en référence à l'histoire du perroquet kulikuli ${ }^{73}:$ «Une grand-mère avait un perroquet. Son petit-fils a voulu le nourrir, mais celui-ci l'a mordu, et a voulu se sauver. En retour, le garçon lui a coupé les deux pattes ». (Kali, 2015)

D'après Alahu, il y avait ici un très ancien village. Elle-même ne l'a pas connu, ni son grand-père, les gens en parlent mais ils n'ont pas connu ce village (fin XIX ${ }^{e}$ ?).

«C'était un grand village avec un tukusipan, et beaucoup de fêtes, beaucoup de rencontres. Certains disent que c'était un village Akaina, d'autres disent que c'était un village wayana. D'après Kulijaman, c'était des Akaina. Un chamane, nommé Paipaso, habitait là. Pïleike ${ }^{74}$ dit que cette région était occupée par les Pasikijana (Pasik c'est le nom de la plume du perroquet ara, qu'on met sur l'épaule). On ne sait pas ce que sont devenus ces Indiens, ils ont disparu, peut-être morts de maladie » (Alahu 2012).

61 - Edouard patatpë (années 1900). Ancien village d'orpailleurs créoles. Ils ne l'ont pas $\mathrm{vu}$, mais en ont seulement entendu parler. 


\section{dire le grand-père d'Amaipoti (Figure 15), gaanman, reconnu officiellement comme le chef suprême des Wayana français par les autorités françaises.}

62-Palakta patatpë (années 1900). Ancien village de Palakta, le père de Twenke, c'est-à-

Figure 15 : Amaïpoti, tepiem au village TIPITI en 1958

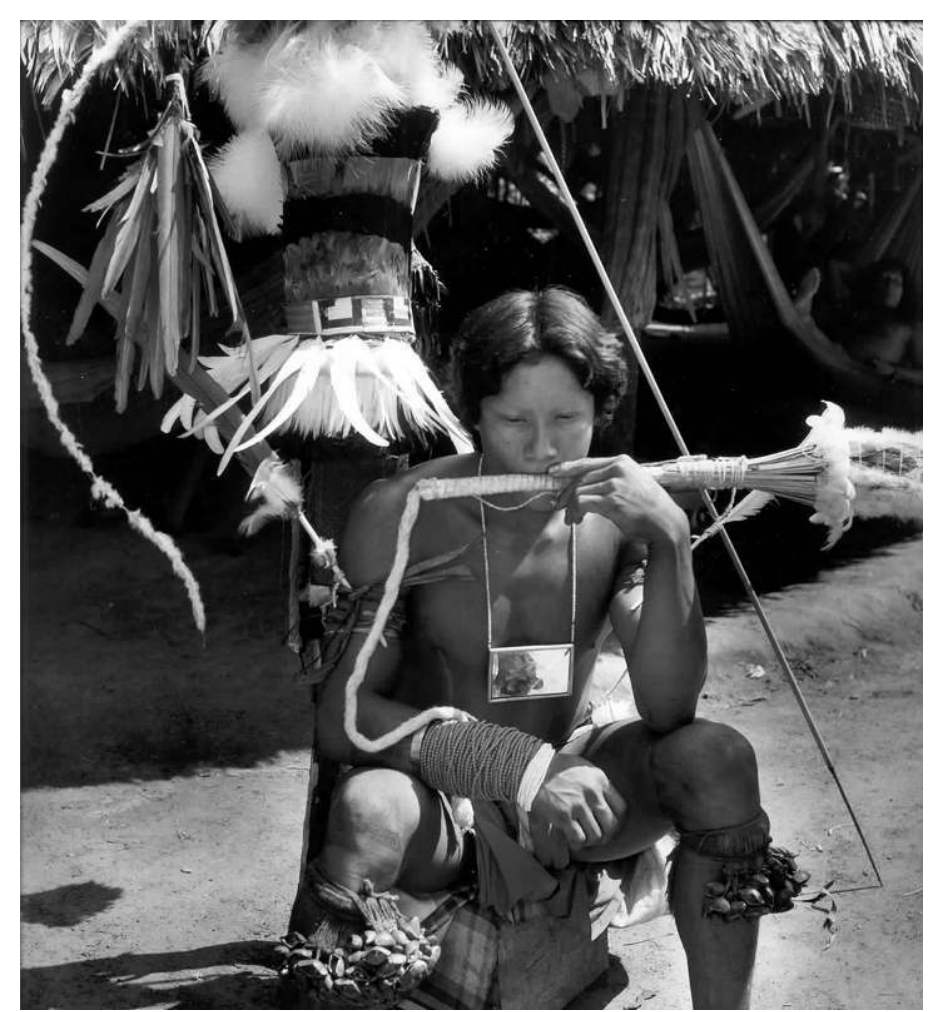

Cliché J. Hurault in Hurault et al. 1998

63 - Malo patatpë (années 1900-1920). Crique Malo avec un ancien village (du temps de Janamale, le père de Kali).

64 - Ilakana patatpë (années 1890-1900). Ancien village de Ilakana : cela date du temps des grands-parents de Kali (sur la crique Malo).

65 - Kumaka inpë, lieu-dit « ancien emplacement de l'arbre fromager ${ }^{75} »$. C'est l'ancien village de Kahka: Kahka patatpë (1900-1920). C'est là qu'il y a eu le premier pendu, le premier suicide ${ }^{76}$, du temps des parents de Kali.

66 - Tëpukuli, « lieu-dit du tëpukuli » (tëpukuli/galet, caillou rond). Une fille est née làbas sur le rocher.

67 - Silipiono, lieu-dit «le trou du silipi ». Endroit où l'on trouve l'arbre aux jolies graines onohkowe (Ormosia sp.).

68 - Tílokolokem, lieu-dit « terre blanche ». C'est juste en face de Silipiono.

C'était l'ancien village de Wapotumït, mais le fondateur du village était Toko, d'où son autre nom Toko patatpë (années 1920-1930).

69 - Mumuluhpan, « lieu des palmiers mumu ${ }^{77}$ ». Lieu-dit sur lequel Wapotumït a fondé un village (Wapotumït patatpë) (années 30-40). C'est là que la grand-mère de Kali est morte. 
70 - Mapikuhpan, ancien village de Paipaso (= Pïleike) Paipaso patatpë (années 20-40). Pidima avait trois ans quand il est allé là-bas (1936).

71 - Jaleïme tupi, lieu-dit « Abattis de Jaleïme » (années 20-30).

72 - Malaitawa patatpë, ancien village de Malaitawa (années 1930 -1940) au lieu-dit Dosinam. C'est là qu'est né Ëputu (1933), le mari de Kali. Pidima l'a connu quand il avait dix ans (1943).

73 - Jephau (années 40). Ancien village : c'était des Wayana qui venaient d'ailleurs (Brésil ou Suriname ?). Pidima l'a connu vers 8-9 ans (1942).

74 - Petikiliki ou Fetikiiki ${ }^{78}$, la " crique où l'on se battait ». Crique avec d'anciens villages de Wama. Certains disent qu'il y a eu des guerres avec les Wama, sur cette crique, mais qu'il n'y avait pas de village. On raconte une histoire qui se déroule là : « il y avait de l'or dans la crique, et les Blancs voulaient faire de l'orpaillage ${ }^{79}$ là-bas : ils sont entrés dans la crique mais un seul est ressorti, blessé par une flèche. Car il y avait des Pijanakoto, tribus sauvages, qui tuaient tous ceux qui approchaient. Ensuite les Blancs sont revenus et se sont vengés en tuant tous les habitants de la crique. Maintenant les orpailleurs sont installés à sa source. Cette crique a vraiment été un lieu de massacre et les gens pourrissaient sur place à cause des épidémies. Il y a eu beaucoup de morts ». (Halanau, 2013).

75 - Palanaiwa patatpë (années 30-40). Ancien village de Palanaiwa (mari de Poika); il vivait avec son beau-père Tiliwé. Pidima était petit. Kali n'a pas connu.

76 - Tule ${ }^{80}$, village de la maman de Pidima (Pilima) (années 30).

77 - En face de Tule il y avait le village de Tulamïtpë, « la souche de l'arbre tula ${ }^{81} »$. (Rive surinamienne, dans les années 30-40) : La famille de Pidima habitait à Tule, quand Pidima était tout petit (il ne marchait pas encore). Il y a eu plusieurs morts, alors ils ont abandonné le village et ont traversé pour aller habiter à Tulamïtpë. La maman de Pidima est morte, et c'est sa tante qui l'a élevé. Ensuite cela a été le village de Janamale quand il avait à peu près 35 ans : Janamale patatpë. Kali a connu ce village abandonné, quand elle avait dix ans (1956).

78 - Helepaike patatpë (années 1920). « Ancien village de Helapaike ». C'était du temps du grand-père de Kali (Alijamalu).

79 - Wapotumït patatpë (années 40). D'abord c'était Malaitawa patatpë, mais quand Poika l'a connu, c'était Losine, le village de Wapotumït

80 - Kawatop, lieu-dit avec campement actuel (celui de Kowe, le gendre de Pidima).

81 - Ewukaj, «celui qui n’a pas d'oeil » (années 1900). Lieu-dit sur une île, avec ancien village sur une autre île du temps de leurs grands-parents.

82 - Tỉlïwe = Pỉleikë patatpë (années 40). Ancien village sur l'île Tỉlïwe. C'était Pïleikë le chef de village (ensuite, ils ont déménagé le village vers Alupentu). Kali a connu ce lieu abandonné quand elle avait 7-8 ans.

83 - Kawatop, nom du saut.

84 - Majuku, île dans les sauts. Majuku c'est le nom de la personne qui est enterrée dans l'île.

85 - Wilipuk patatpë = Tuhwi patatpë, du nom des deux chefs du village (années 1940). Ce village était déjà abandonné quand Kali l'a connu vers 7-8 ans (1954), il date de l'époque de ses parents. 
86 - Taila patatpë, « ancien village Taïla (Kali'na) ». Le village a été brûlé par les Wayana après une dispute, et les Kali'na sont partis.

87 - Alupentu (lieu-dit) : Píleikë patatpë (annnées 60-70). Le fils ainé de Kali, Aseima avait 6-7 ans à cette époque.

88 - Tuhwi patatpë, ancien village de Tuhwi (années 40-50).

89 - Jalu patatpë, ancien village de Jalu (années 40-45).

90 - Paila euku, crique des bois d'arc (paila) située en face de l'Ulemali, rive française. Le village de Jalawale était situé au bord de la crique : Jalawale patatpë (années 1950). Le père de Kali (Janamale) aurait connu ce village quand il était jeune (années 50 ).

91 - Toko patatpë, ancien village de Toko (années 1930-40) sur la petite crique paila euku. Toko était le grand père de Pidima, dont le père a connu ce village.

92 - Ulemali, affluent de l'Alétani. C'était la rivière des Wajalikule.

Effectivement Vidal en 1861, note la

"présence des Oyaricoulets (Wajalikule) entre les criques Wanimari (Ulemali) et Ouei-Foutou (wei-futu) : c'est une tribu d'Indiens avec lesquels les Boni ont été de tout temps en guerre et qui fuient dans les bois, toutes les fois qu'ils voient avancer la plus petite pirogue... » (Vidal 1861).

93 - Kawëmhakan, lieu-dit «la terre en hauteur». Ancien village de Janamale (années 40-50) : Janamale patatpë ${ }^{82}$. C'est ce village qui a été déplacé à Lawa (Anapaïké), à la demande des missionaires évangélistes qui ont créé la mission au lieu-dit de Lawa, en 1948. « Après Kawëmhakan, comme il n'y avait plus de chef, ceux qui sont restés ont fait leur village n'importe comment, comme ils voulaient ${ }^{83}$ » (Kali, 2015) En fait selon différents témoignages, le village aurait persisté avec quelques habitants, au-delà de 1948.

94 - Alphonse patatpë (années1900). Ancien village d'Alphonse (Pierre de son prénom), qui était Taïla (Kali'na). « Les Taïla étaient là depuis très longtemps, avant que les Wayana viennent s'installer » (Pidima, 2015).

Le grand-père de Kali a connu Alphonse, qui était donc encore présent, dans ce village, dans les années 1900. D'après Pidima, les habitants du village seraient ensuite partis vivre à Bigiston, sur le bas-Maroni. Tasikale a connu le petit-fils d'Alphonse à Albina (Suriname) avant sa mort en 1998.

95 - Kuliwa patatpë (années 60). Ancien village de Kuliwa qui était une femme ; Jalukana habitait là aussi. Kuli a connu ce village à l'époque de son premier enfant.

96 - Jakuto uku, saut (uku/pêche en langue aluku).

97 - Kuwahka patatpë (années 1940). Île avec l'ancien village de Kuwahka. Kali ne l'a pas connu, son père était jeune à l'époque de ce village qui se situe dans les sauts de Jakuto uku.

98 - Alawe pan. C'est l'île, sur laquelle on avait abandonné Alawe dans les années 1920, parcequ'elle ne voulait pas épouser l'homme à qui son père la destinait : c'était la famille Wato.

99 - Jalukana patatpë, ancien village de Jalukana.

100 - Wato patatpë (années 1920-30). Ancien village de Atu et de Wato, qui était le grandpère de Pidima, marié avec la grand-mère de Alahu.

101 - Wapahpan (années 1940). Ancien village de Janamale (père de Kali) quand il était jeune (vers 17-20 ans) et n'était pas encore marié. 
102 - Make enï, «trou de Make » (années 40-50). Make était une dame qui était tombée dans l'eau quand elle était bébé, mais qui avait été sauvée in extremis. Il y avait un village à côté, l'ancien village de Panapi (père de Pidima).

103 - Pelea patatpë, ancien village de Pelea (dans l'île) (années 50) : c'était le même village qu'Alakuja : ensuite le chef (tamusi) fut Malavat (Maluwat), le frère de Twenke.

104 - Alakuja patatpë, ancien village d'Alakuja dans l'île (années 60). À la fin, c'était sa femme, Moko, qui avait ce village. Elle est décédée à Anapaiké.

105 - Taponte patatpë, ancien village fondé par Taponte (années 30-40). Grebert (1935) décrit ce village comme étant le plus important village wayana de l'époque.

106 - Silimokale patatpë, ancien village de Silimokale (c'était le grand-père de Nanuk) (années 1900).

107 - Makalahpan, lieu-dit du lieu des arbres Makala ${ }^{84}$, dont les fruits sont mangés par les perroquets. Ancien village de Nanuk: Nanuk patatpë (années 1946-1990). Pierre Grenand a connu ce village en 1965 où vivaient Puptu, Nanuk, Malavat (Grenand comm. pers.).

108 - Panatïlï patatpë, ancien village de Panatïlï. Le père de Kali l'a connu quand il avait 18-20 ans (années 1940-50).

109 - Pidima, aillage actuel de Pidima (Pilima).

110 - Palimino, village actuel où habitent Halanau et son mari Palimino.

111 - Pelea patatpë, ancien village fondé par Pelea.

112 - Kumauhpan, lieu-dit «lieu des papayers» (kumau/papayer85): Twenke patatpë (années 50). C'est l'ancien village de Twenke et de Malavat.

113 - Spider man, village actuel. Ce nom donné par le fondateur du village, souligne l'influence de la télévision et de l'introduction de nouveaux mythes dans la société wayana (Fleury 2010).

114 - Pelea, village actuel.

115 - Palasisi, vllage actuel fondé par Palasisi.

116 - Wapahpan, lieu-dit « lieu des arbres wapa ${ }^{86}$ ", dont le bois est très résistant.

117 - Sauts du Litani : Isolitom, « ensemble des sauts »; isoli//saut, gaan sula en aluku.

118 - Polikumalu, « les poisons coumarous pourris » en langue aluku.

119 - Olosihpan, « lieu des pommes cajous ${ }^{87}$ ».

120 - Akulitiki, « le baton d'Akuli » en langue aluku ».

121 - Atelïme.

122 - Tïwaitïwai, « recule, recule », car le courant force la pirogue à reculer.

123 - Pakilaimë enï, « le trou du pécari à collier géant ».

124 - Aliminaimë enï, « le trou de la gymnote ${ }^{88}$ géante ».

125 - Aliweimë enï, « le trou du caiman ${ }^{89}$ géant ».

126 - Tolinga patatpë, ancien village de Tolinga, gran man des Boni (Aluku), qui était marié avec une femme wayana.

127 - Antecume pata, village actuel d'Antécume fondé par André Cognat en 1967. C'est à présent un des plus gros villages wayana. 
128 - Kumakahpan, lieu-dit « emplacement du fromager » $\left(\right.$ kumaka $\left.^{90}\right)$, village actuel où habitent Kali et son mari Ëputu. 129 - Awalahpan, lieu-dit «emplacement des palmiers Awara ${ }^{91} »$ : village actuel de Taluwen où habitent Tasikale, Aimawale..., fondé par Opoya, le grand-père d'Aimawale (co-auteur de cet article), il est actuellement dirigé par le capitaine Taluwen. C'est un des plus importants villages actuellement sur le Litani avec Antécume pata.

130 - Twenké, village actuel où habitent le grand man Amaïpoti, et le capitaine Haïwe, se situe sur une île juste en face de Taluwen.

131 - Alawata imë enï = babun olo, «le trou du singe hurleur géant » (alawata) : petit village à proximité des villages Taluwen et Twenke.

132 - Lawa, lieu-dit avec village actuel de Anapaïke, principal village wayana sur la rive Surinamienne.

161133 - Awala sula « le saut des palmiers Awara ${ }^{92}$ » en aluku : il y a un village aluku, plus ou moins abandonné actuellement.

134 - Lawa mofu « bouche du Lawa » en langue aluku : c'est ici que se termine le Litani et que commence la portion du fleuve Maroni appelée Lawa.

\section{Les Wayana sur le haut Maroni dans les sources écrites}

Nous allons maintenant comparer nos données issues de la tradition orale avec les sources écrites trouvées dans la littérature, en suivant l'ordre chronologique.

\section{$\mathrm{XVIII}$ siècle : conflits interethniques et occupation progressive du haut Maroni}

La deuxième moitié du XVIII ${ }^{e}$ siècle jusqu'au début du XIX ${ }^{e}$ correspond à une période de guerres très cruelles entre les différents groupes, de chaque côté des Tumuc-Humac. Ces guerres étaient souvent provoquées par des chasses aux esclaves suscitées par les colons européens de l'époque.

\section{La guerre contre les Wayãpi}

Dans les années 1760-1780, des guerres éclatent entre Wayana et Wayãpi. À cette époque les Wayana et leurs alliés occupent les bassins du Jari et du Kouc, les Apalai sont installés sur le Paru de l'Este, et les Wayãpi occupent le moyen Jari et ses affluents. Vers 1760 les Wayãpi attaquent les Upului et les Wayana dans le bas Jari (Grenand 1982). Chapuis (2003, 2007) nous relate ces guerres qui ont eu lieu entre les Wayãpi, notamment les factions nommées Kalaiwa ${ }^{93}$, qui étaient armées par les Portugais pour capturer des esclaves, et les ancêtres des Wayana aux environs du Kouk et du Kuyali, deux affluents du Jari. Il y eut également des conflits avec les autres Wayãpi, notamment sur le Kouk, affluent du Jari au Brésil (Chapuis \& Rivière 2003: 437). Ces guerres étaient très cruelles, les Kalaiwa, également appelés "les Indiens des Portugais» étaient particulièrement craints. Ils furent battus par les Apalai, qui après avoir fait alliance avec eux, les exterminèrent du 
haut Jari et du haut Paru, vers 1830 en les repoussant vers l'est du Jari et le sud-est (Chapuis \& Rivière 2003 : 453).

\section{La guerre contre les Taïla (Kali'na ou Galibi)} effectivement des villages sur bas Litani comme le note déjà P. Grenand en 1982, mais aussi sur le haut Litani (Figure 15). Ce pourrait être à partir de ces villages qu'ils faisaient des raids sur le haut Paru et le haut Jari en empruntant le « chemin des Indiens » liant le haut Litani au haut Jari (en longeant la crique Wamahpan et en traversant le point actuel de trijonction ${ }^{100}$ entre Brésil, Suriname et Guyane française). Les Ancêtres des Wayana ont vécu en paix avec eux durant une certaine période, comme le souligne Pidima. Mais ayant appris qu'ils avaient coupé la tête de l'un des leurs à Mulokotïimë enï, les Wayana laissèrent alors passer les Tililiyo et leurs alliés Kukujana qui poursuivaient les Taïla, depuis le Jari, en allant vers le Nord. Ceux-ci se réfugièrent en amont de l'embouchure de la crique kalakuli euku (crique située un peu en amont de Pidima) : les Taïla sont montés 
sur une colline, où ils se sont fait presque tous tuer. Puis ils sont redescendus à Kupi sula, où ils se font encore poursuivre par les Kukujana ${ }^{101}$. Ils redescendent encore à Luwepan ${ }^{102}$ ( lieu des flutes en bambou ») et jusqu'en amont de Sulaini ${ }^{103}$. Ils franchissent donc les grands sauts, et leurs ennemis abandonnent leur poursuite (Chapuis \& Rivière 2003 : 505). On voit ici se dessiner une frontière physique du pays des Wayana et leurs alliés : les grands sauts du Litani qui furent longtemps infranchissables par des peuples ne possédant pas l'art de la construction des pirogues, contrairement aux Kali'na.

\section{Première présence attestée sur le haut Marouini (1766-1769)}

Si on essaye de retracer l'installation des Wayana en Guyane française à travers les sources écrites, on constate qu'ils se sont réfugiés dans la région des Tumuc-Humac (probablement vers le mont Mitaraka), puis aux sources du Marouini, où les rencontrent Patris, médecin et botaniste du Roy en 1766, et Tony, son accompagnateur, en 1769.

En effet, c'est Patris qui « découvre les Rocoyens » sur le haut Marouini en 1766. Ils sont alors installés sur la crique Amana (probablement la petite crique à l'est du Mont Amana), qui est un affluent du Marouini. Ils sont en lien avec les Amérindiens du rio Coulicary ( Culicari), actuel rio Cuiari, affluent du Jari. Sa description du groupe, chez qui il ne reste que quelques jours, est assez succinte : il décompte 70 à 80 guerriers armés d'arcs et de flèches. Il remarque leurs abattis à flanc de côteau ${ }^{104}$ différents de ceux des Emérillons (Teko), Aramichaux (Alamiso), et Calycouchiens (Kaikusijana), qui préfèrent cultiver les plaines. Il note également leurs interdits alimentaires et sexuels après l'accouchement, la polygamie (surtout chez les chefs), et la nudité des femmes contrairement aux hommes, qui semblent plus couverts. Selon lui la nation des Roucouyennes est considérable, divisée en six peuplades, plus ou moins éloignées les unes des autres, «toutes tirant dans la partie de l'est ", mais il n'a pu en rencontrer que trois durant ce premier voyage (Patris 2001 : 38, 40 et 41). Cette remarque laisse sous-entendre que les Wayana n'auraient pas encore été installés vers les sources du Litani. Toutefois cette conclusion est à relativiser, les voyageurs n'ayant pas été plus loin vers l'ouest, puisqu'ils repartent d' où ils sont venus, c'est à dire vers l'est. Les villages visités sont relativement proches de ceux visités par Crevaux (1883) et Coudreau (1893), une centaine d'années plus tard, laissant entendre une certaine stabilité du groupe dans cette région du haut Marouini.

Lors du deuxième voyage de 1769, Patris et Tony, son compagnon de route passent trois semaines chez les Roucouyennes. Tony ${ }^{105}$ décrit leur organisation militaire de l'époque ${ }^{106}$ et une attitude très méfiante vis-à-vis des visiteurs, étant sans cesse sur leurs gardes.

Lors de ce même voyage, Tony rencontre des Emérillons (Teko) chassés du Maroni par des Tayras (Taïla/Kali'na) qui se sont installés à l'embouchure de l'Inini (un peu en amont de l'actuel bourg de Maripasoula).

En 1789 Leblond, remonte la Camopi et son affluent le Tamouri, à la recherche du Quinquina. Il n'en trouve point, mais rencontre de nombreux villages amérindiens Rocoyennes (Roucouyennes) et Poupourouis (Upului) (33), dont il dresse la liste, de manière précise: Taoua / Saracou / Mourica / Acaoua / Marémarécou / Détiré / Néguéouitt / Jouanapa Neytara / Pépoimé / Arayapouiko / Aramantapi / Coupanampatara / Cayraoua / Morayman / Ouanari / Tounamaypo / Aritué / Ochinengiaporé / Claitari / Alikou / Chouicouppchick / Apok / Capoutak / Conanarimann / Apayakara / Paracouri / Aritouapo / Pranayoua / Aracoua / 
Maygouaré / Ouakinkimpa / Touarinnké (Twenke ?) / Maytaouaré répartis entre la haute Camopi, et le haut Litani (Pouliquen 2001).

Un épisode important intervient ensuite dans l'histoire des Wayana : leur rencontre avec les Boni, qui se réfugient sur le Marouini entre 1793 et $1815^{107}$.

La légende wayana raconte la guerre impitoyable qui eut lieu entre les Boni et les Ndjuka, guerre qui a obligé les Boni à venir se réfugier sur cette rivière, « de la même manière que les Kukujana (ancêtres fondateurs des Wayana) ont été repoussés jusqu'ici par les guerres tribales ». "Les Ndjuka sont venus les harceler jusqu'ici, et il y a eu un affrontement terrible, où tous les Boni ont été exterminés, tous sauf une femme qui était enceinte. Celle-ci s'enfuit dans la forêt et se refugia chez les Wayana, qui la cachèrent dans une jarre à cachiri. C'est ce qui la sauva des Ndjuka. Plus tard, cette femme mit au monde un garçon, avec qui, ensuite, elle fit des enfants ». Selon les Aluku, ce sont eux qui sont allés chercher les Wayana, "alors Indiens sauvages vivant dans les bois", les ont amené à vivre au bord des rivières, et leur ont apporté les premiers objets de la civilisation occidentale. Ils se considèrent un peu comme leurs grands frères protecteurs (Fleury $1999 \mathrm{~b}: 32-33$ ).

Si ces deux versions sont quelque peu romancées, il est certain que ces quelques années de contact étroit entre les deux populations ont été très importantes pour les deux groupes : les Boni apprirent aux Wayana à construire de solides canots monoxyles, qui vont leur permettre ensuite de franchir les grands sauts du Litani. Les Aluku apprirent de nombreuses techniques des Wayana, dont certainement la culture et la transformation du manioc amer. En effet, durant la période des guerres contre les Hollandais, ils cultivaient préférentiellement du riz pluvial et des tubercules (Fleury 1996). Les longues et complexes techniques de détoxification du manioc amer furent certainement transmises des Wayana aux Aluku, ou du moins améliorées, durant cette période où ils vivaient en étroit contact les uns avec les autres.

Nous allons voir que les Boni eurent également une forte influence sur le mode de vie des Wayana, qui maîtrisant de mieux en mieux les rivières, se rapprochèrent effectivement de leurs rives, et purent conquérir progressivement les berges du Litani, établissant des liens commerciaux avec les Boni, qui leur servaient d'intermédiaires avec le littoral, pour les ravitailler en outils métalliques (haches, sabres, couteaux...) en perles et en tissu.

En1815 les Boni redescendent vivre sur le Lawa, sur les lieux de leurs anciens villages.

\section{$\mathrm{XIX}$ siècle : une présence assurée sur les criques formatrices (Alama, Sinale) des deux affluents du Maroni : Litani (Aletani) et Marouni (Mawina) (Figure 15)}

La situation générale semble apaisée quand Vidal, Crevaux puis Coudreau retrouvent les Wayana sur le haut Maroni vers la fin du XIX ${ }^{\mathrm{e}}$ siècle.

Vidal en 1861 , lors de sa reconnaissance du Litani ${ }^{108}$, rencontre les Wayana, qu'il nomme Roucouyennes, à l'embouchure de la crique Alama dans un petit village (Alama patatpë ?) de cinq cases habitée par trois familles. D'après l'auteur, le village a été fondé uniquement dans le but de faciliter le commerce avec les Boni (alors installés sur le Lawa). Le reste de la population vivant de l'autre côté des Monts Tumuc-Humac (sur le Jari). Toutefois il avait croisé un peu plus en aval, un nouvel abattis avec quelques carbets et deux ou trois indiens (probablement un nouveau village en construction). 

e siècle (1870-80). fait sur la crique Wamahpan. (Sinale). (Coudreau, 1893 : 82). la crique Mamilihpan : (Pidima, 2013).

En réalité, il y a eu d'autres villages en amont sur la crique Alama vers les Tumuc-Humac, car d'après Coudreau (1893), il y avait un ancien village à deux jours de marche de l'embouchure en longeant la crique Alama, au pied d'une petite montagne. Ce village était déjà abandonné, quand il y est passé en 1887. On peut supposer qu'il datait de la fin du XIX

Crevaux (1883) remonte le Maroni dans le but d'atteindre les monts Tumuc-Humac, qu'il veut traverser. Il rencontre le premier village Roucouyenne au bout de 16 jours de canot, et parvient au bout de 33 jours, au dégrad où les Indiens laissent leur canot pour traverser à pied la ligne de partage des eaux jusqu'au Brésil. Ce qui laisse sous-entendre la présence des Wayana, à mi-chemin. Malheureusement Crevaux, terrassé par la fièvre, ne donne guère de précision permettant de reconnaître l'emplacement de ce village Roucouyenne (apparemment le seul sur le Litani, à l'époque). Il en repart avec une escorte de trente Indiens Roucouyennes, dont Apoiké. À l'étude de la carte, il est fort probable que ce village soit le même que celui que Coudreau décrit ensuite comme étant Pikiolo, c'est à dire à l'embouchure de la Mamilihpan.

Crevaux emprunte le chemin des Wayana qui conduit par les Tumuc-Humac au versant brésilien. Il nous dit longer la rive droite de la crique Coulé-Coulé (Kule-Kule), mais la desciption des chuttes d'eau d'une hauteur de 15 mètres, nous prouve qu'il se trouve en

Coudreau (1893), quant à lui décrit très bien le village de Pililipou (Figure 4) où il séjourne plusieurs semaines. Sa description précise du chemin emprunté durant trois jours de marche en forêt, permet de situer ce village entre les criques affluentes de l'Alama et de la Sinale. Il situe le village à $30 \mathrm{~km}$ du Mitaraka. Selon lui, «les Roucouyennes ne possèdent au nord des Tumuc-Humac que les trois centres de Pililipou, Apoiké et Piquiolo », et «ils n'ont de relations ni avec les Emérillons (Teko), ni avec les Oyampi » (Wayãpi) (Ibid : 118). Il nous évoque la " présence ancienne, 150 ans auparavant », (c'està-dire au milieu du XVIII ${ }^{e}$ siècle), « d'un grand village Roucouyenne du Marouini, village de guerre, d'où l'on dominait quinze lieues des Tumuc-Humac occidentales, d'Adidonbogogoni, aux chaînes qui s'étendent vers l'Oyapock. D'après la tradition le plateau de Pililipou était alors un lac, qui s'est depuis écoulé par la crique Chinalé»

«La paix a déjà été scellée avec les Boni sur la crique Koutou, entre les grand man Anato pour les Boni, et le chef Twenke (ou son père) pour les Wayana » (Coudreau 1893).

Coudreau désigne l'Itany (Litani) comme la grande route des Roucouyennes (Wayana) :

« ceux du Jary et du Parou y arrivent par le sentier de l'Apaouni (Mapahoni) et la descendent pour se rendre à Cottica ${ }^{109}$. De nombreuses traces de passage attestent la fréquence de leurs voyages durant cette saison favorable aux déplacements »

À l'époque le premier village roucouyenne rencontré en remontant le Litani est Pikiolo "petit trou» (pikin/petit; olo/trou) en langue aluku ${ }^{110}$, à proximité de pikin sula («petit saut» en aluku, apsik isolï en wayana), (petit village qui selon Coudreau, n'existait pas en 1877 lors du passage de Crevaux). Or, le petit saut se situe à proximité de

«C'est à son embouchure qu'Alinkana est descendu jusqu'au premier saut et a construit son village : c'était Pële imë enï (le trou du poisson-roche géant) » ${ }^{111}$ 
Ce nom difficilement prononçable par les étrangers avait été probablement plus ou moins traduit par les Boni par Pikin olo ${ }^{112}$ : «le petit trou», en référence au trou du poisson roche.

En cette fin du XIX $x^{e}$ siècle, on assiste donc au début de la descente du Litani par les villages wayana.

Notons que Coudreau rencontre les Kali'na, qu'il nomme Calinas, en aval du saut Gaan Man Ponsu (vers Kawatop), Amérindiens qu'il confond avec les Roucouyennes, avec lesquels ils étaient à l'époque alliés. Leur présence sur la rivière à cette époque corrobore la mémoire orale des Wayana qui les situe un peu en aval de Kawatop, village qui aurait été par la suite brûlé après une dispute avec les Wayana. Ils seraient ensuite partis définitivement à Bigiston (bigi/gros; ston/caillou, rocher en aluku).

Coudreau note aussi la présence des Oyaricoulets (Wajalikule) près du canal des Hollandais, bras de la rivière récemment élargi. Il précise

"Quand il était plus étroit, on y trouvait fréquemment embusqués, des canots Oyaricoulets qui guettaient au passage Boni et Roucouyennes ». « Depuis qu'ils ont fait fuir les Trios, les Oyaricoulets occupent tout le versant occidental inférieur et moyen de l'Itany: Ulemali, Luwe depuis Lawa mofu tabiki, jusqu'à Gaan Sula » (Coudreau 1893: 81).

Cette portion de la rivière correspond plus ou moins à celle occupée par les Wayana contemporains entre Anapaïke (Lawa) et Antécume pata (gaan sula) (Figures 8 et 9). On comprend donc que ce sont ces Amérindiens si redoutés à la fois par les Wayana et les Noirs marrons qui bloquaient alors l'installation des Wayana plus bas sur la rivière. À l'époque, le "pays des Roucouyennes » comme on appelle alors les Wayana, commence donc à Kawatop en aval de la crique Ulémali, occupée par les Oyaricoulets, mais leur installation véritable dans des villages ne dépasse pas la crique Maliliihpan.

Entre temps, en 1885, le grand man Anato et ses hommes ont découvert des gisements d'or sur le Lawa. M. Vitalo, orpailleur créole arrivé par l'Inini, les fait connaître, ce qui attire l'immigration importante d'orpailleurs créoles antillais dans la région (Henry 1974).

\section{$\mathrm{xX}$ e siècle : la sédentarisation des villages sur le bas Litani}

Au tout début du xx siècle (années 1900-1920), les Wayana qui maitrisent maintenant la confection des canots en bois selon la technique transmise par les Noirs marrons, franchissent les sauts. Ils occupent vers 1900 le moyen Itani, jusqu'aux grands sauts du Litani. Nous avons relevé 18 villages qui datent de cette époque des grands-parents de nos accompagnateurs. C'est une période de paix, mais c'est aussi le début de la ruée vers l'or sur le Maroni, d'où quelques villages d'orpailleurs créoles sur le Litani.

7 Pour les années 1920-1940, sont répertoriés une vingtaine de villages entre la crique Sinalepan et l'amont des grands sauts du Litani.

En 1935, Grebert indique un grand village roucouyenne sur la rive française du Litani : Taponte. Il dénombre alors trois villages sur cette rive française, et deux autres plus petits sur la rive hollandaise. Il souligne que le gouvernement hollandais semblait à l'époque se désinterresser des Amérindiens, mais qu'il semble vouloir revenir sur ses erreurs en les attirant à l'emplacement de l'ancien village de Calacouli-Touna. Il précise également que les Amérindiens sont en perpétuel mouvement et qu'ils vont fréquemment 
rendre visite à leurs familles restées au Brésil, en passant par le sentier des Amérindiens qui fait communiquer les versants français et brésilien des Tumuc-Humac.

Il indique que le chemin passait autrefois par la crique Coulé Coulé (kule kule), mais qu'un autre chemin demandant plus de trajet par rivière, mais moins de marche à pied passe par la Wamahpan. Au Mont «Temomaïrem, un village a été établi par la mission française ». Il décrit l'habitat des Wayana avec des cases collectives, et nous renseigne sur la manière d'établir un nouveau village, en commençant la première année par un abattis. Si celui-ci avait un rendement satisfaisant, on établissait alors le village au milieu de l'abattis (Grebert 1935).

\section{Les années 1940-50 : une dizaine de villages se répartissent entre Kawatop et les sauts du Litani.}

En 1948, des missionnaires américains créent une mission évangéliste à Lawa et proposent à Janamale de déplacer son village situé à Jakutouku. Celui-ci accepte mais luimême se sentant trop âgé, il laisse le pouvoir à Anapaïke. Certains Wayana l'ont suivi, d'autres ont préféré s'installer ailleurs.

1961: André Cognat, originaire de Lyon, s'aventure chez les Wayana où il finira par s'installer définitivement, en créant le village d'Antécume pata en 1967.

À l'époque Tolinga, chef Boni, avait son village dans les sauts du Litani, et André a dû lui demander l'autorisation de s'installer dans les sauts, juste en face.

Les villages de Twenke, Anapaïké, Elahé et Wempi (actuel Kayodé) existaient déjà en 1961. Un autre village important sur le plan culturel existait sur le Marouini (actuellement déserté) : le village de Tipiti qui se situait juste en aval des grands sauts du Marouini (Cognat 1967)

En 1968 J. Hurault nous livre dans son ouvrage sur la culture matérielle des Wayana, la répartition des villages ${ }^{113} \mathrm{du}$ sud au nord avec le nombre de familles. On constate que les villages se répartissent alors de part et d'autres des grands sauts du Litani. C'est le début de la sédentarisation des habitats.

Tableau 1 - Villages installés en aval des sauts du Litani (Hurault 1968)

\begin{tabular}{|c|c|c|c|}
\hline Nom du village & Etat & Lieu dit & Nombre de familles \\
\hline Ilikwa & Suriname & Alawakumta & 4 \\
\hline Elahé & France & Alawakumta & 4 \\
\hline Pîleiké & Suriname & Kitiima ponjou & 5 \\
\hline Anapaïké & Suriname & Awara soula & 16 \\
\hline Touanké & France & Doméké & 8 \\
\hline
\end{tabular}

Tableau 2 - Villages installés dans les sauts du Litani (Hurault 1968)

\begin{tabular}{|c|c|c|c|}
\hline \multicolumn{1}{|c|}{ Nom du village } & Etat & Lieu dit & Nombre de familles \\
\hline Aloiké & France & Akoulitiki & 5 \\
\hline Tiliwe & France & Kassiaba soula & 6 \\
\hline
\end{tabular}


Tableau 3 - Villages installés en amont des sauts du Litani (Hurault 1968)

\begin{tabular}{|c|c|c|c|}
\hline \multicolumn{1}{|c|}{ Nom du village } & Etat & Lieu dit & Nombre de familles \\
\hline Tipiti & France & Sipalipata & 6 \\
\hline Malavat (Malawat) & France & Paou pepta & 3 \\
\hline Nanou (Nanuk) & Suriname & Paou pepta & 2 \\
\hline Yaloukana (Jalukana) & Suriname & Kawatop & 7 \\
\cline { 2 - 4 }
\end{tabular}

Il precise que Touanké (Twenke) est le chef des Wayana côté français et qu'Anapaïké (à Lawa) est contrôlé par la mission du Révérent Jackson.

L'auteur dénonce déjà les effets déletères sur les Amérindiens de leur contact avec les Européens et les Créoles, avec pour effet la «mendicité, l'alcoolisme et l'affaiblissement de la morale » (Hurault 1963).

\section{Analyse des toponymes}

L'analyse des toponymes nous renseigne sur la perception de la nature, certains éléments, anecdotes et événements de la vie des Wayana d'autrefois, et aussi l'importance des fondateurs des villages.

On peut distinguer deux catégories de toponymes :

- ceux fondés sur des éléments du paysage (plantes, animaux, monstres)

- et ceux qui font référence à des fondateurs de village et autres personnages importants dans l'histoire wayana.

Les toponymes de la première catégorie, utilisés pour désigner les lieux-dits, cours d'eau, sauts, sont riches d'enseignements sur la perception de l'environnement (Fleury 1999b, Chapuis 2003) et sur la culture wayana. En effet, sur plus de 130 toponymes, une vingtaine de lieux-dits utilisent des noms de végétaux, et une dizaine ceux d'êtres monstrueux (Tableaux 4 et 5).

Ceci nous montre la place importante que prennent les arbres et autres végétaux comme marqueurs de paysage. Le plus souvent ce sont des plantes utiles à l'homme dans l'alimentation (fruits de palmiers), l'artisanat (palmiers, arouman, fève tonka...) ou les rituels (roucou). Nous avons également quelques toponymes liés à la présence de ressources animales (escargots d'eau douce, poissons), soulignant leur importance dans l'alimentation, ou encore les fourmis rouges pour leur nuisance.

210 Enfin soulignons l'importance des animaux mythiques (tulupele, alawataimë, pakilaimë, mulokotiïmë...) dans la toponymie. Les mythes racontent comment le guerrier Kalaiwa a terrassé tous les fauves (félins) monstrueux des inselbergs (Chapuis \& Rivière 2003). Nous avons vu dans un des récits, qu'il doit également terrasser les monstres aquatiques mangeurs d'hommes, symbolisant les dangers de la rivière, par exemple Tulupele, mijaguar, mi-chenille, qui terrorisait les Amérindiens, en les dévorant. Seule la paix et l'union entre les peuples apalai et upului (ancêtres des Wayana) ont pu venir à bout de ce monstre qui bloquait la rivière. C'est en découpant sa peau ornée de jolis dessins, que les Amérindiens reçoivent les différents motifs de la vannerie (Davy 2007, Van Velthem 1998). Le jaguar (istaino) et la chenille (ëlukë) sont toujours très représentés dans les motifs ornant les objets faits en vannerie et en perlerie (Fleury 1999b, 2010)

211 Ces monstres aquatiques sont présents sur toutes les rivières habitées par les Wayana (Jari, Paru et Maroni) où l'on retrouve les mêmes mythes, notamment celui de Tulupele s'y référant (Van Velthem 1998). Longtemps habitants des forêts, les Wayana se sont 
rapprochés des rivières pour en apprivoiser les berges, et en franchir les sauts grâce aux pirogues d'abord en écorce, puis en bois. Cet apprentissage de la rivière s'est fait au prix de nombreuses victimes, comme nous avons pû le constater tout au long des récits.

Tableau 4 - Nom des végétaux utilisés dans les toponymes du Litani

\begin{tabular}{|c|c|c|}
\hline Awalahpan Awala sula & Lieu des Awara le saut des Awaras & Astrocaryum vulgare, Arecaceae \\
\hline Bois de rose pata & Village du « bois de rose » & Aniba rosaeodora, Lauraceae \\
\hline Elewe & Ananas sauvages & Ananas ananassoides, Bromeliaceae \\
\hline Kulumulihpan & Lieu des bambous & Guadua Iatifolia, Poaceae \\
\hline Kumakahpan & Lieu du fromager & Kumaka/Ceiba pentandra \\
\hline Kumauhpan & Lieu du papayer & Carica papaya, Caricaceae \\
\hline Kumupisa watpë & Lieux où l'on coupe les grappes de comou & Oenocarpus bacaba, Arecaceae \\
\hline Majahpan & Lieu des manguiers & Mangifera indica, Anacardiaceae \\
\hline Makalahpan & Lieu du makala & Endopleura uchii, Humiriaceae \\
\hline Malipahpan & Lieu des maripa & Attalea maripa, Arecaceae \\
\hline Mamilïhpan & Lieu de la liane franche & Mamilïhle/Heteropsis flexuosa, Araceae \\
\hline Mapikuhpan & Lieu des mapiku & Dipteryx odorata, Fabaceae \\
\hline Olosihpan & Lieu des pommes cajou & Anacardium occidentale, Anarcardiaceae \\
\hline Onohkowe & Lieu des Ormosia & Ormosia coccinea (Aubl.), Ormosia spp., Fabaceae \\
\hline Onotapotop & Lieu ou les tepiem s'enduisaient de roucou & Onot/Bixa orellana, Bixaceae \\
\hline Pajhapan & Lieu des herbacées & Herbacées \\
\hline Palulu sula : paluluimë & Saut des balisiers (nom aluku) & $\begin{array}{l}\text { Palulu (aluku) ou Paluluimë (wayana)/Phaenakospermum } \\
\text { guyannense, Musaceae }\end{array}$ \\
\hline Sihnatëpan & Lieu des lianes & Sihnat/lianes \\
\hline Tamaniwahpan & Lieu de tamaniwa & Pradosia surinamensis, Sapotaceae \\
\hline Wamahpan & Lieu des Indiens Wama (arouman) & Wama//schnosiphon arouma, Marantaceae \\
\hline Wapahpan & Lieu des wapa & Wapa/Eperua falcata, Caesalpiniaceae \\
\hline
\end{tabular}

Tableau 5 - Noms des êtres monstreux utilisés dans les toponymes du Litani

\begin{tabular}{|c|c|c|}
\hline Alawataimë enï & Trou du singe hurleur géant & Singe hurleur (Alouatta seniculus, Cebidés) \\
\hline Aliminaimë enï & Trou de la gymnote géante & Electrophorus electricus, Electrophoridés \\
\hline Aliweimë enï & Trou du caïman géant & Paleosuchus palbebrosus, Crocodilidés \\
\hline Kulimawuimë enï & Trou du pak géant & Kulimawu/pak (Agouti paca, Agoutidae) \\
\hline Mulokotïmë enï & Trou du mulokot géant & Mulokot/monstre aquatique \\
\hline Pakilaimë enï & Trou du pakira géant & Pakira/Tayassu tajacu,Tayassuidés \\
\hline Pëleimë enï & Trou du poisson roche géant & Pële/Pseudancistrus barbatus, Loricariidés \\
\hline Pomuimëenï & Trou des mouches géantes & Pomu/mouche \\
\hline Sililiimë enï & Trou du sili géant & Sili/oiseau cotinga de Cayenne (Cotinga cayana, Cotingidés) \\
\hline Silipipiimë enï & Trou du silipipi géant & Silipipi/tyran féroce (Myarchus ferox Fluvicolinés). \\
\hline Tulupele kaimotatpë & Trou de Tulupele & Monstre de la mythologie (cf encart) \\
\hline
\end{tabular}

\section{Toponymes faisant référence à de personnages importants}

212 En fait la plupart des noms de villages portent le nom du fondateur du village, soulignant l'importance du primo-arrivant. Cette habitude persiste pour les noms des villages contemporains, avec un changement de nom quand la personne décède : le village porte alors le nom du descendant du fondateur, considéré comme le chef du village (tamusi). Notons que ce sont, à quelques exceptions près, toujours des hommes. Cette habitude était déjà soulignée par Leblond en 1789: « Le nom de chaque village prend ordinairement celui du capitaine, surtout s'il en est le fondateur » (Pouliquen 2001).

La transmission des noms est importante chez les Wayana qui possèdent un corpus de noms qui se transmettent après la mort, en principe à leurs petits-enfants : on réserve parfois des noms pour certains héritiers. Cette importance des patronymes est bien soulignée dans le mythe du guerrier Kailawa, qui conserve les noms des enfants raptés lors de ses razzias pour fonder la société wayana. Il constitue ainsi un véritable patrimoine anthroponymique transmis jusqu'à nos jours. 
214 Une cinquantaine de noms de villages portent le nom des fondateurs de villages, tous amérindiens : Alakuja, Alawata, Alinkana, Aloike, Aluwakali, Apipa, Atilupïn, Helepaike, Ilakana, Jalukala, Jalepo, Jalu, Jalawale, Janamale, Jaleimë, Jamaikë, Janamale, Kahka, Kwahka, Kulikuli, Kumalaikë, Kupi, Kwana, Lapo, Malaitawa, Malo, Opoya, Paipaso, Palanahwa, Palanaiwa, Palakta, Palasisi, Palimino, Panapi, Panatele, Pelea, Pidima, Pïleikë, Silimokale, Taponte, Tasikale, Tëpukuli, Toko, Tuhwi, Twenke, Wato, Wapotumït, Wilïpuk...

215 D'autre toponymes (souvent situés plus en aval) contiennent des noms ou des termes non amérindiens comme Edouard (prénom d'un Créole), Alphonse (nom d'un Kali'na), Palulu sula (aluku), Koboi sula (aluku), Bois de rose (français)

Tous ces noms de lieux empruntés à d'autres langues soulignent les contacts interculturels qui ont eu lieu lors de la migration des Wayana, le long du Litani entre le $\mathrm{XIX}^{\mathrm{e}}$ et le $\mathrm{XX}^{\mathrm{e}}$ siècle (Fleury \& Alupki 2014). Ces contacts, parfois conflictuels, ont participé à la génèse de la société wayana contemporaine.

\section{Conclusion}

217 Les lieux-dits font souvent référence à des ressources végétales, plus rarement animales, pour la nourriture et l'artisanat. Mais il faut aussi souligner l'importance des noms de monstres aquatiques comme autant de notifications de dangers potentiels. Ces montres sont souvent représentés dans les motifs de l'artisanat traditionnel, comme la vannerie, perlerie et le ciel de case (maluwana) (Van Velthem 1998, 2003 ; Fleury sous presse).

218 La plupart des villages portent le nom de leurs fondateurs. Tous ces patronymes constituent un patrimoine important, comme nous l'avons vu dans le mythe fondateur des Wayana. En jalonnant les territoires ancestraux, ils marquent de leur empreinte immatérielle l'histoire et les territoires wayana.

219 Ces enquêtes nous ont permis également d'enregistrer la mémoire orale attachée à ces lieux, par des prises de vue vidéo et photographiques. Il s'agit maintenant de trouver un moyen de restituer ce patrimoine immatériel à travers un média adapté, la carte sur papier n'en représentant qu'une modeste partie.

S'il mérite d'être approfondi et surtout étendu au Marouini, ce travail nous renseigne néanmoins sur l'histoire des Wayana à travers le temps et l'espace :

221 La conquête du Litani s'est faite après de nombreuses guerres sanglantes, et d'épidémies ${ }^{114}$. Les guerres intertribales du XVIII ${ }^{\mathrm{e}}$ siècle ajoutées aux hécatombes dues aux épidémies ont entraîné une telle chute démographique que les groupes ont dû s'unir et faire la paix, $\mathrm{au} \mathrm{XIX}^{\mathrm{e}}$ siècle pour ne pas disparaître. Cette « union qui fait la force » est bien illustrée dans le mythe de Tulupele (cf. encart et Van Velthem 1998). De cette union est né le peuple wayana, qui est resté en gestation jusqu'à la fin du XIX ${ }^{e}$ siècle: c'est l'époque où les peuples apprennent à vivre ensembles dans la région du haut des rivières formatrices du Maroni. C'est seulement au $x^{e}$ siècle que les Wayana descendent le long du Litani et du Marouini jusqu'à l'emplacement des villages actuels.

L'étude de la toponymie du Litani nous éclaire donc sur l'histoire des Wayana, à travers leur inscription spatio-temporelle en Guyane. Ce travail n'est pas seulement utile pour alimenter la carte de la Guyane des toponymes wayana, il permet aux jeunes Wayana de se répproprier leur histoire territoriale. 
Il nous renseigne également sur leur perception de l'environnement (inselberg, forêt, rivière...) à travers les récits et les mythes dressant un paysage peuplé de fauves et de monstres dévoreurs d'hommes. Ceux-ci sont là pour rappeller aux humains, que la nature ne leur appartient pas, mais qu'elle est sous l'emprise de puissants esprits. La conquête du Litani a donc été gagnée après de nombreuses épreuves, contre les peuples ennemis, mais aussi les dangers de la rivière.

La constitution de l'ethnie wayana s'est passée de manière concomittante à cette appropriation du Litani, les Wayana se distinguant de leurs "Ancêtres sauvages » qui vivaient dans la forêt, encore sous l'emprise de celle-ci, comme les êtres itupon, entités floues entre animalité et humanité. La vie à découvert le long des rivières permet, selon les Wayana, le passage à la civilisation, en même temps que le rapprochement des biens occidentaux, mais se fait au détriment de la connaissance chamanique et magique des plantes et de la forêt (Chapuis 2003).

Pascale de Robert et Roselis Mazurek pour leurs nombreux conseils et encouragements. Pidima, Halanau, Haiwe, Kali, Ëputu, Poika, Alahu, Mimisiku, Barbo, André Cognat et tous les Sachants qui nous ont permis de reconstituer leur histoire.

Pierre et Françoise Grenand pour leur relecture, leurs encouragements et le prêt des photos de Jean Hurault.

Jean Hurault pour la confiance qu'il m'a témoignée et les magnifiques photos qu'il nous a laissées. Les habitants wayana du Litani, pour leur accueil, leur collaboration, et leur amitié.

L'IRD et notamment le PPR AMAZ dirigé par Laure Emperaire pour une partie des financements. Le projet DIPOLOPP (programme GUYAMAZON-IRD) dirigé par Pascale de Robert pour une partie des financements.

Pierre Joubert et Pauline Perbet du Parc Amazonien de Guyane (PAG), pour la réalisation des cartes toponymiques.

Amandine Courte pour la réalisation des cartes historiques du haut Litani.

\section{BIBLIOGRAPHIE}

Camargo E. \& Tapinkili 2009 - Dictionnaire bilingue wayana-français / Hakëne omijau eitop wajanapalasisi. CNRS-CELIA UMR 8133, DRAC de Guyane, Tekuremai. [En ligne : https://www.vjf.cnrs.fr/ celia/FichExt/Dic_alphas/wayana_francais/index.htm]

Chapuis J. \& Rivière H. 2003 - Wayana eitoponpë. (Une) histoire (orale) des Indiens Wayana. Matoury, Éditions Ibis rouge, 1065 p. [En ligne : http://classiques.uqac.ca/contemporains/chapuis_jean/ Wayana_eitoponpe/Wayana_eitoponpe.pdf]

Chapuis J. 2003 - Le sens de l'histoire chez les Indiens wayana de Guyane. Une géographie historique du processus de « civilisation ». Journal de la Société des Américanistes 89 (1) : 187-209.

Chapuis J. 2007 - L'ultime fleur. Ekulunpï tihmelë. Essai d'ethnosociogénèse wayana. Encyclopédie wayana. Orléans, Presses Universitaires Orléans, 164 p.

Cognat A. 1967 - J'ai choisi d'être indien. Paris, Flammarion, 250 p. (l'aventure vécue). 
Collomb G. \& Tiouka F. 2000 - Na'na Kali'na. Une histoire des Kali'na en Guyane. Matoury, Ibis rouge Editions, $144 \mathrm{p}$.

Coudreau H. 1893 - Chez nos indiens : quatre années dans la Guyane française (1887 - 1891). Paris, Hachette.

Crevaux J. 1883 - Voyages dans l'Amérique du Sud. Paris, Hachette.

Davy D. 2007 - Vannerie et Vanniers : approche ethnologique d'une activité artisanale, Thèse de Doctorat, Université d'Orléans, $526 \mathrm{p}$.

Duin R. 2004 - Ethno-archaeological reconnaissance in the Wayana homeland. Report of the Kailawa expedition in southwestern French Guyana, October 17-November 10, 2004, ms

Duin R. 2014 - Historical complexity of myth: in search of the genesis of the whip-dance whereby Wayana dance in imitation of Tamok (Eastern Guiana Highlands). Boletim do Museu Paraense Emílio Goeldi. Ciências Humanas 9 (3) : 741-772.

Dupuy F. (Ed.) 2012 - Les arpenteurs des confins. Explorateurs de l'intérieur de la Guyane (1720-1860). In La librairie des cultures 4. Paris, CTHS.

Fleury M. 1991 - Businenge : Les "Hommes-forêt". Essai d'Ethnobotanique chez les Aluku en Guyane française. Thèse de l'Université Paris VI, 367 p.

Fleury M. 1996 - Plantes alimentaires et identité culturelle chez les Marrons Boni (Aluku) de Guyane française. In Hladik C.M. et al. (Ed.) L'Alimentation en forêt tropicale. Interactions bioculturelles et perspectives de développement. Paris, Unesco MAB : 973-984. (L'homme et la biosphère).

Fleury M. 1999a - Maripasoula. Premiers villages aluku du Maroni in Bilan scientifique (année 1999). Recherches ethno-archéologiques. DRAC Guyane. Service archéologique.

Fleury M. 1999b - Dénomination et représentation des végétaux en forêt tropicale : étude comparative chez les Amérindiens wayana et les Noirs marrons aluku de Guyane francaise. In Bahuchet S., Bley D., Pagezy H., Vernazza-Licht N. (Ed.) L'homme et la forêt tropicale, ChateauneufGrasse, Ed de Bergier, SEH : 31-44.

Fleury M. 2010 - Du mythe de la nature au mythe du monde moderne : représentation du monde et modernité chez les Amérindiens wayana. In Amaz'hommes. Sciences de l'homme et sciences de la nature en Amazonie. Matoury, Ibis Rouge Editions : 217-234.

Fleury M. sous presse - Artisanat wayana-apalai. DVD interactif. Cayenne, Editions GADEPAM.

Fleury M. \& Alupki T. [2014] - [Communication orale] Participatory mapping and oral memory: Wayana of French Guiana on the tracks of their history. Conférence au colloque International d'Ethnobiologie. Bhutan. Juin 2014.

GEPOG 2003 - Portraits d'oiseaux guyanais. Matoury, Ibis rouge editions, $479 \mathrm{p}$.

Grenand P. 1982 - Ainsi parlaient nos ancêtres. Essai d'ethnohistoire wayãpi. Paris, ORSTOM, 408 p. (Travaux et documents de l'ORSTOM ; 148).

Grenand P., Moretti C., Jacquemin H. \& Prévost M.-F. 2004 - Pharmacopées traditionnelles en Guyane. Créoles, Wayãpi, Palikur. Bondy, IRD éditions, $816 \mathrm{p}$.

Henry H. 1974 - La Guyane française. Son histoire 1604-1946. Cayenne, Imprimerie Paul Laporte, $320 \mathrm{p}$.

Kulijaman M. \& Camargo E. 2007 - Kaptelo. L'origine du ciel de case et du Roseau à fleches chez les Wayana (Guyanes). Cayenne, Editions GADEPAM-CTHS, 112 p.

Hurault J. 1968 - Les Indiens wayana de la Guyane française. Paris, ORSTOM, 152 p. 
Hurault J. 1972 - Français et Indiens en Guyane. Cayenne, Guyane Presse Diffusion, 223 p.

Hurault J., Frenay P. \& Roux Y. 1963 - Pétroglyphes et assemblages de pierres dans le sud-est de la Guyane française. Journal de la Société des Américanistes 52 : 157-166.

Hurault J., Grenand F. \& Grenand P., 1998 - Wayana et Wayãpi de la forêt. Bondy, IRD Editions, 198 p. (Autrement).

Moomou J. 2004 - Le monde des Marrons du Maroni (1772-1860). La naissance d'un people : les Boni. Matoury, Ibis rouge Editions, $216 \mathrm{p}$.

Patris J.-B. 2012- Relation abrégée d'un voyage fait dans l'intérieur de la Guyane française en remontant l'Oyapock, le Camoupy etc, et descendant le Marony, après avoir pénétré dans les terres Presque jusqu'aux sources de ce dernier fleuve [1766-1767]. In Dupuy F. (Ed.) Les arpenteurs des confins. Explorateurs de l'intérieur de la Guyane (1720-1860). Paris, CTHS, (La librairie des cultures ; 4).

Pouliquen M. 2001 - Les voyages de Jean-Baptiste Leblond, médecin naturaliste du roi. 1767-1802. Antilles, Amérique espagnole, Guyane. Paris, Editions CTHS, 340 p. (format ; 47).

Robert P. de \& Fleury M. 2012 - Plantes, lieux, objets et mots : marqueurs territoriaux et identitaires, indicateurs de dynamiques socioenvironnementales et patrimoniales. Rapport de recherche PPR-AMAZ. Brasilia, IRD.

Tony 2012 - Voyage dans l'intérieur du continent de la Guyane chez nos Indiens Roucoyens (1769). In Dupuy F. (Ed.) Les arpenteurs des confins. Explorateurs de l'intérieur de la Guyane (1720-1860). Paris, CTHS (La librairie des cultures ; 4).

Vidal G. 2012 - Voyage d'exploration dans le haut Maroni (Guyanes française et hollandaise) (1861). In Dupuy F. (Ed.) Les arpenteurs des confins. Explorateurs de l'intérieur de la Guyane (1720-1860). Paris, CTHS (La librairie des cultures ; 4).

Van Velthem L.H. 2003 - O belo é a fera. A estética da produção e da predação entre os Wayana. Lisboa, Museu nacional de etnologia Assirio \& Alvim.

Van Velthem L. H. 1998 - A pele de Tuluperê: uma etnografia dos trançados Wayana. Belém, Museu Paraense Emílio Goeldi.

\section{NOTES}

1. Cette région a inspiré nombre d'explorateurs, comme Raymond Maufrais, qui a péri sans jamais l'atteindre.

2. La forêt qui couvre $95 \%$ du territoire de la Guyane française appartient à l'État et le Parc Amazonien de Guyane (3,3 millions d'hectares) a été créé en 2007 sur le tiers sud du territoire. C'est dans cette région, que vivent trois des six communautés amérindiennes peuplant la Guyane : Wayãpi, Teko, Wayana auxquelles se sont aggrégés des Apalai et des Tïlïyo venus plus récemment du Brésil.

3. Les Wayana connaissent encore l'origine de leur clan, Upului, Kukujana, etc. liée à des caractéristiques physiques.

4. La dernière carte touristique du territoire éditée par le PAG a déjà pris en compte quelquesunes de nos données de terrain que le PAG, en la personne notamment de Pierre Joubert, a bien voulu repositionner sur les cartes IGN de la région. 
5. Cette convention précise que les données issues de l'étude sont la copropriété de KALIPO et du MNHN et qu'elles peuvent faire l'objet de publications scientifiques dans des revues spécialisées. Des restitutions publiques sont également prévues sur le territoire concerné.

6. Signifie aussi « Ancien », " grand-père ».

7. La migration s'est faite parallèlement par un autre grand affluent du Maroni, le Marouni (Mawina). La toponymie du Marouini également travaillée durant ces deux missions donnera lieu à une autre publication.

8. L'étymologie est celle proposée par Tasikale au cours de notre travail, revue si possible à l'aide du dictionnaire Wayana-Français (Camargo \& Tapinkili 2009).

9. Carbet collectif construit dans le village pour y accueillir les fêtes traditionnelles et qui sert aussi de case de passage aux étrangers.

10. De pija/aigle harpie, Harpia harpia, Accipitridae: ces Amérindiens étaient réputés rapides et féroces comme cet aigle (Chapuis 2003). Ils seraient une des composantes des actuels Tiliiyo.

11. De nombreuses grottes parsèment cette région d'où prennent leurs sources nombre d'affluents de grands fleuves.

12. Ce n'est pas sans nous rappeler la remarque de Pidima sur l'origine des Amérindiens Apalai : «ce sont les descendants d'un grand inselberg, situé au Brésil : Ëhapëtëtpë. On y trouverait des os dans les rochers » (Pidima, 2013).

13. Alimina en langue wayana et en latin : Electrophorus electricus, Electrophoridés.

14. Kulima en apalai, kulimau en wayana : cassique à huppe noire, Psarocolius decumanus Pallas (Icteridae) (Grenand comm. pers.).

15. Pan suffixe signifiant lieu actuel, inpë suffixe signifiant ancien lieu, kulumuli/bambou, Guadua latifolia (Humb. et Bonpl.) Kunth, Poaceae.

16. Selon Tasikale, le père de Twenke l'ancien et celui de Janamale seraient partis de Kulumulihpan. Twenke l'ancien est l'ancêtre de Twenke qui a fondé le village du même nom sur le bas Litani. D'après Coudreau (1893 : 104), il « appartient à une vieille famille roucouyenne qui depuis longtemps donne des tamouchis (tamusi : chef, Ancien) aux Roucouyennes du Marouini et de l'Itany » (Litani).

17. On retrouve ici l'antagonisme entre le pouvoir de procréation et l'art de la guerre déjà souligné ailleurs, notamment chez les Noirs marrons (Businenge) (Fleury 1991).

18. Cette assertion concernant le bambou Guadua latifolia est retrouvée chez les Wayãpi, les Palikur et de nombreux autres groupes amazoniens. Les études chimiques réalisées ont montré la présence de coumarine, qui pourrait expliquer l'action anti-coagulante de la plante. (Grenand et al. 2004 : 565-566).

19. Les Kukujana, qui ont disparu en tant que groupe ont fusionné pour une part avec les Tïliyo, et de l'autre avec les Wayana (Chapuis \& Rivière 2003). Le chef Twenke et sa lignée sont des descendants des Kukujana, parfois appelés Wayana ale (« les vrais Wayana »).

20. D'autres récits situent le village du partage (Etakpatpïtpë), qui remonte à l'époque de Kailawa, plus haut dans les Tumuc-Humac.

21. Brosimum guianense, Moraceae.

22. Wama en wayana désigne l'arouman, Ischnosiphon arouma (Aubl.) Körn, Marantaceae.

23. Chef wayana qui a fondé plusieurs villages.

24. Alahu est une femme âgée qui vit près du village de Kumakahpan avec son mari. Nous l'avons rencontrée et interrogée en novembre 2012 en préparation de notre mission de reconnaissance.

25. Cette remarque nous éclaire d'un fait intéressant confirmé par la note sur Wamahpan: les ancêtres des Wayana ne maîtrisaient pas la fabrication des flèches (avec les pointes en bambou) avant l'échange avec le groupe étranger de Kulumulihpan. Cela explique pourquoi les ancêtres des Wayana craignaient tellement les Amérindiens Wama, qui fabriquaient des flèches en arouman et pouvaient atteindre leurs cibles de loin. Il est vrai que l'instrument de guerre des Wayana semblait surtout être le kapalu, casse-tête, avec lequel ils assommaient et éclataient la 
cervelle de leurs ennemis, en les surprenant dans leur sommeil. Au fur à à mesure des alliances avec d'autres groupes, les techniques de guerre se sont enrichies.

26. Ces pierres empilées rappellent celles décrites par Hurault et al. (1963) sur l'inselberg de la borne Un. À ce sujet voir aussi Duin (2004)

27. Mulokot : être aquatique dangereux pouvant attaquer les hommes. Il fait partie des ipo (Kulijaman \& Camargo $2007: 88$ ).

28. Ce terme est aussi utilisé pour désigner le village Kulumulihpan : inpë signifiant ancien emplacement, pan signifiant simplement emplacement.

29. La création d'un nouveau village était soumise à autorisation auprès du chef de village de Kulumulihpan, qui dominait donc la région à cette époque $\left(\mathrm{xVIII}^{\mathrm{e}}\right)$.

30. Cet élément nous permet de comprendre que ce village est issu des habitants du premier village kulumulihpan, c'est-à-dire des Kukujana associés à des Apalai, des Païla ou des Taïla (selon les versions).

31. Ipo : nom générique utilisé pour désigner tous les monstres aquatiques dévoreurs d'hommes. Le même terme ipo existe en Wayãpi pour désigner les créatures de l'eau (Grenand comm. pers.)

32. Avec le soutien des Hollandais, les Kali'na ont établit des villages permanents sur le bas Itani et le bas Marouini pour servir de base à des expéditions qui leur permettaient d'enlever des femmes, mais aussi des hommes et des enfants qu'ils vendaient comme esclaves à Paramaribo (Collomb \& Tiouka 2000). Soulignons que c'est la première fois qu'on localise un village kali'na si haut sur le Litani.

33. Chapuis (2007) le situe sur le haut Jari. Toutefois l'emplacement de ce lieu sur le haut Litani, nous paraît cohérent avec l'histoire.

34. Groupe éteint du haut Camopi (Grenand comm. pers.)

35. C'est Apatou, guide aluku, qui accompagnait Crevaux (1883) puis Coudreau (1893) dans leurs missions, qui l'a certainement baptisé ainsi.

36. Candidat au maraké (rite d'initiation incluant l'imposition d'insectes)

37. Paniers tressés en arouman, dans lesquels les invités apportent la pâte à cachiri pour la fête du maraké.

38. Kikiwi : tyran quiquivi, Pitangus suphuratus, Tyrannidés (GEPOG 2003).

39. Alama : abeille; alamakaikusin : le fauve de l'inselberg Tëwalunem (Chapuis \& Rivière 2003).

40. Ces Alamayana (ou Alamajana) se sont battus contre les « indiens des Portugais » vers 1736 sur le Couyari, affluent du Jari (Tony 1969).

41. Coudreau (1893) décrit aussi « la bananeraie naturelle de l'Alameapo, de chaque côté d'une petite crique, un «tigre " y étant jadis redouté ». Notons toutefois que les bananiers communs (Musa spp.) ne sont pas originaires d'Amérique, ils y ont été introduits vers 1500 ; il peut s'agir d'anciennes plantations d'autres groupes amerindiens ou bien des formations de bananiers sauvages ( paluluimë), espèce locale (Phaenakospermum guyannense, Sterlitziaceae) dont les fruits sont comestibles, sans être savoureux.

42. Marie Fleury lors de l'expédition Planète revisitée, programme co-organisé par le Muséum National d'Histoire Naturelle et l'ONG Pro-Natura International, qui s'est déroulé au mont Mitaraka en mars 2015.

43. Ceryle torquata, Alcedinidae

44. Aniba rosaedora : cet arbre dont le bois contient une huile essentielle très recherchée par les parfumeurs, a donné lieu à une exploitation intensive qui a entraîné une raréfaction de la ressource et une cessation de l'exploitation. http://www.guyane.cnrs.fr/spip.php?breve45. Il est désormais inscrit sur la liste des espèces protégées en Guyane.

45. Arbre (Couratari guianensis, Lecythidaceae) dont l'écorce battue en lanière est utilisée pour faire les masques de danses okalat et tamok.

46. Un masque similaire a été acquis par le Musée de l'Homme auprès de l'association GADEPAM à Cayenne pour être exposé dans une des vitrines de la galerie de l'Homme. 
47. Le narrateur nous précise qu'il existe une histoire similaire sur le Jari (Pidima, 2013).

48. Endopleura uchii, Humiriaceae

49. Cf. mythe restitué en encart

50. Hymenaea courbaril, Caesalpiniaceae

51. On évoque certainement ici, le deuxième Kailawa, celui de la paix, car les Wayana ont déjà amorcé la conquête du fleuve.

52. À propos de ce mythe voir aussi Van Velthem L. H. (1998)

53. Siparuna guianensis Aubl., Siparunacaea

54. Siparuna decipiens (Tul.) A. DC.

55. Ces arbustes dégagent une odeur très caractéristique.

56. Ethnie d'Amérindiens venant du Jari au Brésil

57. vivant sur le Tapanahoni

58. Ara ararauna, Psittacidae, (Chapuis 1998).

59. Plante épiphyte, Heteropsis flexuosa (Kunth) Bunting, Araceae, très recherchée pour la vannerie.

60. Pële : poisson-roche (Pseudancistrus barbatus, Loricariidé).

61. Ananas ananassoides (Baker) L.B.Sm., Bromeliaceae

62. Pradosia surinamensis (Eyma) T.D.Penn., Sapotaceae

63. Attalea maripa (Aubl.) Mart., Arecaceae

64. Bixa orellana L., Bixaceae

65. Parkia pendula (Willd.) Benth.ex Walp, Mimosaceae

66. Asolene sinnamarina, Ampullariidae

67. Ce nom signifie « esprit du feu », c'était le père du chamane Pïleike. De Goeje a connu ce cheflà dans les années 1930 (Grenand comm. pers.)

68. On note ici le grand respect pour les rochers et les inselbergs, dont sont issus certains peuples dans la tradition.

69. Tuna : eau, crique, rivière.

70. Alawata : Alouatta seniculus, Cebidés.

71. Cotinga de Cayenne. Cotinga cayana, Cotingidae.

72. Voir supra

73. Amazone poudrée. Amazona farinosa, Psittacidae.

74. Ancien Chamane, maintenant décédé.

75. Ceiba pentandra (L.) Gaertn., Bombacaceae.

76. Cette information permettant de «dater» l'arrivée des suicides chez les Wayana est importante. En effet, on assiste actuellement à une vague de suicides chez les Autochtones en Guyane, ainsi selon l'association ADER - Actions pour le développement, l'éducation et la recherche - on compte chez les Wayana un suicide pour 200 habitants, soit vingt-cinq fois plus qu'en métropole. https://www.senat.fr/questions/base/2014/qSEQ14120426G.html

77. Mumu : palmier épineux à fruits comestibles Astrocaryum sciophilum (Miq.) Pulle, Arecaceae

78. «Quand Kailawa a fait le partage, Les Wama ont demandé ce côté-ci, il leur a donné la crique Petikiliki (ou fetikiiki en langue aluku : feti/guerre, combat ; kiiki/crique). Avant il n'y avait pas de village par ici. Ils ont trouvé un endroit, ils ont fait leur village et sont restés longtemps là-bas. Moi je ne l'ai pas vu, mon père et mes grands-pères les ont connus. À l'époque il n'y avait pas de papier, mais on l'a appris par la transmission orale » (Pidima, 2013).

79. Des gisements aurifères ont été découverts par le grand man Boni Anato et ses hommes sur le Lawa, mais ils ne furent connus qu'à l'arrivée dans la région en 1885 d'un Créole, M. Vitalo, venu de l'Approuague par l'Inini : il prospecta la zone, et la trouva très riche (Henry 1974: 215). Cette découverte entraîna une ruée vers l'or dans la région, avec l'arrivée de nombreux Créoles antillais. Le village créole Édouard, est certainement issu de cette époque. 
80. Tule est le nom d'une danse, que l'on pratique avec les instruments de musique tule (clarinettes fabriquées en bambou, luwe).

81. Tula : Canari macaque en créole, Lecythis zabucajo Aubl., Lecythidaceae.

82. Village photographié par Dominique Darbois en 1951, avec Palanam et Kali enfants (Indiens d'Amazonie, Editions mondiales. Texte de Francis Mazière. Photographies de Dominique Darbois).

83. Cette information est intéressante, car elle nous renseigne sur l'impact déstructurant sur la société, de l'évangélisation des Wayana.

84. Endopleura uchii, Humiriaceae.

85. Carica papaya L., Caricaceae.

86. Wapa : Eperua falcata Aubl., Fabaceae.

87. Oloï : Anacardium occidentale, Anacardiaceae.

88. Alimina/gymnote électrique, Electrophorus electricus, Electrophoridés.

89. Aliwe : caiman à front lisse : Paleosuchus palbebrosus, Crocodilidés.

90. Ceiba pentandra (L.) Gaertn, Bombacaceae.

91. Astrocaryum vulgare Mart., Arecaceae.

92. Astrocaryum vulgare Mart., Arecaceae.

93. Ce nom désigne les Portugais en référence à l'alliance de ces Amérindiens avec les Portugais (Grenand comm. pers.). Dans les textes anciens, on les appelle aussi les «Indiens des Portugais» (Tony 1969).

94. Peuple karib vivant actuellement sur le littoral de tout le plateau des Guyanes du Venezuela jusqu'à l'Amapá.

95. «Clan des lucioles » (kukui/lucioles) : ils étaient réputés voir la nuit grâce à l'usage de torche faites avec des écorces pilées (certainement à base d'encens). Ce clan a ensuite été absorbé en partie par les Tïlïyo, mais aussi en partie par les Wayana (Chapuis \& Rivière 2003 : 505).

96. Mulepan toponyme existant apparemment également sur le Jari (comme de nombreux toponymes que l'on trouve sur plusieurs rivières). Mais nous pensons là, contrairement à Chapuis, qu'il s'agit de Mulepan sur le Litani (cf. carte).

97. Dans les chants de guerre du Kalau relevé par J. Hurault, le $9^{\mathrm{e}}$ chant évoque une guerre sans merci contre les Kalipono (ennemis). La fin du chant aborde le monstre Mulokotïimë enï, ce qui conforte l'hypothèse d'un combat à proximité de ce lieu (Hurault 1968).

98. Kijapok/oiseau toucan.

99. J. Chapuis situe la crique Mapahoni sur le haut Jari, mais selon nos relevés elle se situe en aval de la crique Malo sur le Litani.

100. Kulimapopan en Wayana (Kulimau/cacique huppé, Psarocolius decumanus, Icteridae).

101. D'après le conteur Kuliyaman, les Kukujana possédaient des remèdes qui les empêchaient de se faire tuer, notamment des incantations magiques (Chapuis \& Rivière 2003).

102. Situé selon nos relevés entre la crique Malo et les sauts Kawatop.

103. C'est ainsi que les Aluku nomment les grands sauts de Kotika.

104. Ce goût à cultiver les terres escarpées perdure jusqu'à nos jours, la raison invoquée de ce choix étant le meilleur écoulement des eaux de pluies.

105. C'est le seul témoignage qui nous reste de ce deuxième voyage, Patris ayant perdu toutes ses notes dans un naufrage.

106. Les Amérindiens étant à l'époque soumis à une pression très forte de la part des autres groupes, notamment les Wayãpi armés par les Portugais ( $c f$. infra).

107. $C f$. article de Fleury \& Hurault (à paraître).

108. Suite à cette mission de délimitation de la frontière franco-hollandaise, le Maroni fut ouvert à la circulation, et les Boni libérés de la tutelle des Ndjuka imposée par les colons hollandais (Hurault $1972: 89$ ).

109. Village ou étaient installés les Boni 
110. Ce qui souligne bien les contacts fréquents entre les deux groupes

111. Pële : poisson roche (Pseudancistrus barbatus, Loricariidé).

112. De la même manière on assiste actuellement à la fréquente traduction du lieu-dit Alawataimë enï (trou du singe hurleur géant) par Babun olo (le trou du singe hurleur en langue aluku).

113. On voit des photos prises dans les villages à cette époque dans l'ouvrage de Hurault, Grenand \& Grenand 1998.

114. Si 30000 Amérindiens peuplaient la Guyane, au moment de la conquête, ce nombre est tombé à 1200 en 1964. On assiste ensuite à un redressement démographique lié à une politique sanitaire plus efficace (Hurault 1972: 5). Si les épidémies ne sont pas soulignées dans les récits cités dans notre article, elles sont encore bien présentes dans la mémoire orale.

\section{RÉSUMÉS}

La genèse du peuple wayana est située dans les Monts Tumuc-Humac à l'extrême sud de la Guyane. En perpétuel lien avec les populations du Brésil, vivant sur le Jari (actuellement abandonné), et le Paru de l'Este, ils ont vécu longtemps de part et d'autre de la ligne de partage des eaux, entre les affluents de l'Amazone et du Maroni.

Cet article repose sur un travail de cartographie participative mené avec les Wayana entre 2012 et 2015 pour retrouver et parcourir les anciens sites habités sur le haut Litani. Il s'appuie sur la tradition orale, mais aussi les textes écrits des explorateurs ayant sillonné la région et des anthropologues. Il retrace la migration progressive des Wayana depuis les Tumuc-Humac jusqu'au bas-Litani, où ils vivent encore actuellement. La toponymie nous renseigne sur la perception de la nature, les fondateurs des villages, et les rencontres souvent conflictuelles avec d'autres peuples et êtres monstueux. En effet, cette migration s'est faite dans un contexte de guerres (interethniques et coloniales), et d'attaques de monstres aquatiques symbolisant les dangers de la rivière. C'est une véritable conquête du Litani qui nous est donc livrée ici à travers différents témoignages et des cartes permettant de spatialiser l'histoire des Wayana sur cette rivière.

The genesis of wayana people is located in the Tumuc-Humac area in the far south of French Guyana. In everlasting bond with the people of Brazil, living on the Jari (now abandoned), and Parou of Este, they lived a long time on both sides of the divide line between the tributaries of the Amazon and Maroni. This article is based on a participatory mapping work conducted with the Wayana between 2012 and 2015 to find and browse the oldest inhabited sites on the upper Litani. It is based on the oral tradition, but also the texts of the explorers and anthropologists who have travelled the area. It traces the gradual migration of Wayana from Tumuc-Humacs to low-Litani, where they still live today. The toponymy tells us about the perception of nature, the founders of the villages, and often conflicting encounters with other peoples and monstrous beings. Indeed, the migration took place in a context of war (ethnic and colonial), and attacks of aquatic monsters attacks symbolize the dangers of the river. It is a real conquest of the Litani that is delivered here through various accounts and cards and maps allowing us to spatialize the history of the Wayana on this river. 
INDEX

Keywords : Wayana, Litani, history, participatory mapping, toponymy, French Guyana Mots-clés : Wayana, Litani, histoire, cartographie participative, toponymie Index géographique : Guyane française

\section{AUTEURS}

\section{MARIE FLEURY}

Ethnobotaniste au Muséum National d'Histoire Naturelle, UMR 208 PALOC, MNHN-IRD Directrice de l'antenne du MNHN en Guyane, IRD 9016597323 Cayenne cedex

\section{TASIKALE ALUPKI}

Président de l'Association KALIPO, association loi 1901 ayant pour objectif de valoriser l'artisanat traditionnel Wayana, Apalai et Tiriyo du Haut-Maroni, promouvoir la culture et assurer la transmission des savoirs et savoir-faire traditionnels, Village Taluwen.

\section{AIMAWALE OPOYA}

Traducteur wayana-français, habitant du village de Taluwen

\section{WAISO ALOÏKÉ}

Guide, traducteur, piroguier, village de Taluwen 